Cahiers $d u$ MONDE RUSSE

\section{Cahiers du monde russe}

Russie - Empire russe - Union soviétique et États indépendants

$41 / 4 \mid 2000$

Aperçus sur le monde juif

\title{
Les corps d'ingénieurs comme forme d'organisation professionnelle en Russie
}

Genèse, évolution, spécificité (XVIII ${ }^{\mathrm{e}}-\mathrm{XIX}^{\mathrm{e}}$ siècles)

Dmitri Gouzévitch et Irina Gouzévitch

\section{(2) OpenEdition}

\section{Journals}

Édition électronique

URL : https://journals.openedition.org/monderusse/60

DOI : 10.4000/monderusse. 60

ISSN : $1777-5388$

Éditeur

Éditions de l'EHESS

\section{Édition imprimée}

Date de publication : 1 octobre 2000

Pagination : 569-614

ISBN : 2-7132-1383-5

ISSN : $1252-6576$

Référence électronique

Dmitri Gouzévitch et Irina Gouzévitch, « Les corps d'ingénieurs comme forme d'organisation professionnelle en Russie », Cahiers du monde russe [En ligne], 41/4 | 2000, mis en ligne le 15 janvier 2007, consulté le 15 septembre 2022. URL : http://journals.openedition.org/monderusse/60 ; DOI : https://doi.org/10.4000/monderusse.60 


\title{
LES CORPS D'INGÉNIEURS COMME FORME D'ORGANISATION PROFESSIONNELLE EN RUSSIE
}

\author{
Genèse, évolution, spécificité (XVIII et XIX ${ }^{\mathrm{e}}$ siècles)
}

LE CORPS TECHNIQUE EST NÉ DU BESOIN DE RÉGULARISER, en l'institutionnalisant, l'activité d'un groupe professionnel nombreux et hétérogène, celui des ingénieurs au début du XVIII ${ }^{\mathrm{e}}$ siècle. Une fois mise sur pied et éprouvée, cette forme d'organisation professionnelle s'est avérée suffisamment efficace pour que nombre de pays du monde entier s'en dotent progressivement au cours des deux siècles suivants. Elle connaît d'abord une extension rapide dans le domaine du militaire : ainsi la plupart des armées du monde s'adjoignent des corps techniques militaires, des artilleurs et des ingénieurs militaires en premier lieu. Par contre, les corps techniques fonctionnant indépendamment des forces armées n'ont connu qu'une expansion relativement réduite par rapport à leurs homologues militaires. On les trouve, cependant, dans la plupart des pays européens tels que l'Espagne, les États allemands, la Suède, et surtout la France, championne classique des organisations de ce type.

L'histoire des divers corps techniques nationaux a fait l'objet de nombreux travaux ${ }^{1}$. Cependant, exploré par les chercheurs occidentaux des pays concernés, ce thème reste toujours en marge des intérêts des historiens russes. Et ceci bien que

1. Une bibliographie exhaustive reste à faire, nous nous contentons d'offrir ici, à titre d'exemple, une liste sélective qui ne tient compte que des travaux les plus connus. Cf. : Alvin, « Le Corps des officiers géographes », Bulletin SAS École Polytechnique, 98, avril 1940, pp. 15-19; Bicentenaire du Génie maritime 1765-1965, Paris, Éd. S.P.E.I., 1965, 291 p.; A. Brunot, R. Coquand, Le corps des Ponts et chaussées, Paris, CNRS, 1982, 915 p.; F. Fichet-Poitrey, J. Bureau, M. Kaufmann, Le corps des Ponts et chaussées du génie civil à l'aménagement du territoire, Paris, 1982, 230-XXX p.; A. Guillerme, Corps à corps sur la route : les routes, les chemins et l'organisation des services au XIX siècle, Paris, Presses de l'École nationale des ponts et chaussées, 1984, 172 p.; Id., Bâtir la ville : révolutions industrielles dans les matériaux de construction : France, Grande-Bretagne (1760-1840), Seyssel, Champ Vallon, 1995, 320 p.; 
l'exemple de l'Empire russe, très peu connu en Occident comme d'ailleurs en Russie même, soit unique en son genre car l'organisation professionnelle des ingénieurs sous forme de corps techniques y avait atteint, au cours des XVIII et XIX ${ }^{\mathrm{e}}$ siècles, un degré de perfection et de sophistication extrême. Malgré cela, les travaux de synthèse sur ce sujet - en russe comme en toute autre langue - font toujours cruellement défaut.

Autant de raisons de rendre justice aux pionniers qui se sont récemment hasardés sur ce terrain. Leurs tentatives, encore isolées et tâtonnantes, d'aborder ce sujet extrêmement complexe et confus font preuve d'une grande intuition professionnelle, mais elles souffrent d'imperfections factuelles et d'insuffisances méthodologiques. Tel est, par exemple, le cas de l'ouvrage d'O. Kryštanovskaja, l'un des rares dans la littérature soviétique à traiter des problèmes de l'institutionnalisation du métier de l'ingénieur ${ }^{2}$. Très instructif sur le plan sociologique, il présente des faiblesses dans sa partie historique où l'on constate un mélange anachronique de faits et de dates souvent imprécis et mal vérifiés. Parmi les rares chercheurs occidentaux à s'être intéressés à la genèse du génie russe, Alfred Rieber occupe une place importante ${ }^{3}$. Ce chercheur américain fut l'un des premiers à établir des parallèles pertinents entre l'organisation du génie en France et en Russie. Cependant, outre quelques imprécisions ${ }^{4}$, ce travail présente des interprétations et des affirmations parfois discutables, imputables à la fois à la complexité du sujet et aux prises de position de l'auteur. Certains aspects de cette problématique ont été également examinés par les historiens des sciences et des techniques s'intéressant aux relations transnationales, tels les chercheurs britanniques M. Bradley, R. P. Bartlett et A. G. Cross ${ }^{5}$.

«Istorija upravlenija Korpusom mostov i dorog vo Francii », Zurnal Ministerstva putej soobščenija, 10, 1868, bibl.pp. 2-5; « Konduktory putej soobščenija vo Francii », Ibid., 9, 1868, otd. III, pp. 262-284; Ibid., 10, 1868, otd. III, pp. 51-80; «Upravlenie putej soobščenija i publičnyh rabot vo Francii », Ibid., 3, 3-4, 1866, neof. otd., pp. 121-160; de Lastours, « Les services publics qui se recrutent à l'École », Bulletin SAS École Polytechnique, 10, 15 févr. 1930, pp. 18-48; Id., X Information : Bulletin mensuel polytechnicien, 5-7, oct.-déc. 1929, pp. 83-85, 126-129; A. Picon, Architectes et ingénieurs au siècle des Lumières, Marseille, Parenthèses, 1988, 318 p.; Id., L'invention de l'ingénieur moderne : l'École des ponts et chaussées, 17471851, Paris, Presses de l'École nationale des ponts et chaussées, 1992, 768 p.; J.Pritchard, « From shipwright to naval constructor: The professionalization of 18th-century French naval shipbuilders », Technology and Culture, 28, 1, janv. 1987,pp. 1-25; M. Čerepašinskij, Očerk istorii mostov, č. 1 : Derevjannye i kamennye mosty, Moscou, 1898, 187 p., ici p. 113.

2. O. V. Kryštanovskaja, Inženery : Stanovlenie i razvitie professional'noj gruppy, Moscou, Nauka, 1989, 144 p.

3. A. J. Rieber, « The rise of engineers in Russia », Cahiers du Monde russe et soviétique, 31, 4, 1990, pp. 539-568.

4. Les erreurs de ce genre sont assez nombreuses mais faciles à corriger; elles proviennent essentiellement, nous semble-t-il, des sources secondaires à la disposition de l'auteur lors de la préparation de son article (et en tout cas de celles que l'auteur cite dans son annexe bibliographique) et de l'impossibilité de les vérifier dans les sources d'archives localisées en Russie.

5. Roger P. Bartlett, « The recruitment of foreign canal engineers for Russia under Catherine II », Study Group on Eighteenth-Century Russia: Newsletter, 4, 1976, pp. 43-51; Id., «Scottish cannon-founders and the Russian Navy, 1768-1785 », Oxford Slavonic Papers, N. S., X., 1977, pp. 51-72; Id., « Charles Gascoigne in Russia : A case study in the diffusion of British technology, 1786-1806 », in Russia and the West in the eighteenth century, Newton- 
Nous nous sommes proposés ici de tenter une réflexion sur la genèse et l'évolution des corps techniques dans l'Empire russe, sans aborder toutefois la comparaison de ces structures avec leurs homologues occidentaux ${ }^{6}$. Une autre raison a également guidé notre choix : tous les documents statutaires relatifs à la fondation et/ou à la réorganisation des corps techniques - décrets, manifestes, règlements - étaient émis de Saint-Pétersbourg, résidence impériale qui, à ce titre même, abritait toutes les administrations relevant de l'État. Par cette facette, notre étude s'intègre, d'une part, dans l'histoire des administrations impériales et, de l'autre, dans l'histoire du développement des organisations professionnelles d'ingénieurs dans la région pétersbourgeoise.

\section{Quelques considérations d'ordre terminologique}

Au préalable, il semble utile d'expliciter les notions opérationnelles de base de cette recherche ainsi que nous les comprenons.

Le corps est un organisme professionnel d'État hiérarchisé selon des grades personnels (en russe čin) ${ }^{7}$; ses membres y exercent un service effectif qui peut être obligatoire et qui leur procure l'essentiel de leurs revenus. Les effectifs du corps sont généralement limités en nombre, ce nombre est régi par un état prévisionnel des personnels qui tient compte des postes (fonctions) du service d'État susceptibles d'être occupés par les représentants d'un corps donné.

Le grade personnel reflète le niveau de formation de l'individu, sa qualification, ses mérites professionnels et, en partie, son ancienneté dans le service.

Le čin définit la place de son porteur dans la hiérarchie générale du service. De ce point de vue le grade personnel peut jouer le rôle de dénominatif ou de définition orale du čin. Il existe cependant certains grades individuels dont la corrélation avec les činy est indirecte ou nulle, tels les grades d'honneur (membres étrangers et honoraires des académies, universités, comités scientifiques, etc.) ou certains grades de fonction (zvanie po dolžnosti, par exemple aide de camp, général-aide de camp, etc.). Les dénominations des činy relèvent des dénominations des fonctions.

ville, MA, Oriental Research Partners, 1983, pp. 354-367; Id., « The Russian nobility and the Baltic German nobility in the eighteenth century », Cahiers du Monde russe et soviétique, 34, 1-2, 1993, pp. 233-244; M. Bradley, « Franco-Russian engineering links : The careers of Lamé and Clapeyron, 1820-1830», Annals of Science, 38, 1981, pp. 291-312 ; A. G. Cross, « John Phillips, canal enthusiast in Russia, 1783-1785 », Study Group on Eighteenth-Century Russia : Newsletter, 1, 1973, pp. 36-40.

6. Une telle analyse dépasserait de loin les limites d'un article. Les auteurs ne perdent pas l'espoir de tenter d'écrire un jour une monographie sur ce thème car, au cours d'un travail de plusieurs années, ils ont déjà accumulé un riche matériel sur l'histoire des administrations techniques, des corps de métier et des organisations professionnelles en Russie et en Europe depuis le Moyen Âge.

7. Sur la notion de čin dans la culture russe médiévale et sur la polysémie de ce terme, cf. L. A. Černaja, «O ponjatii ‘čin' v russkoj kul'ture XVII veka », Trudy otdela drevnerusskoj literatury, (Saint-Pétersbourg), 47, 1993, pp. 343-356. 
La classe (selon la Table des rangs) est un numéro d'ordre du čin dans l'échelle hiérarchique définie par la Table.

Le rang constitue une unité désignant à la fois la classe d'un fonctionnaire et les fonctions auxquelles il peut accéder. Ce terme est parfois utilisé comme synonyme de la classe et du čin.

À la différence des organisations administratives auxquelles ils étaient directement liés, les corps en Russie étaient censés gérer essentiellement les problèmes d'effectifs, sans toucher aux questions de gestion, de conduite des travaux, d'enseignement ou autres ${ }^{8}$.

De ce point de vue une administration (direction, collège, département, comité, commission) revêt un caractère purement bureaucratique tandis qu'un corps serait plutôt une structure organisée selon un mode bureaucratique sans nécessairement assurer de fonction de gestion. Cela tient au fait que, dans un pays comme la Russie, les ingénieurs regroupés au sein d'un corps ont le statut d' « ingénieurs d'État » et, par cette position même, sont intégrés dans son élite bureaucratique. Et ceci bien que les fonctions de ces deux groupes soient très différentes. Si la bureaucratie est appelée à assurer la gestion, les ingénieurs, quant à eux, sont censés assurer intellectuellement le processus de production alors que la gestion de la production ne constitue qu'une facette de cette activité intellectuelle.

Les corps peuvent être classés en quatre catégories : corps militaires, militarisés, semi-militarisés et civils. Regroupant les fonctionnaires d'État, ils rendent floue la démarcation habituelle entre les ingénieurs en service militaire et les ingénieurs en service civil. Pour les États où les ingénieurs sont organisés en corps, la division de ces derniers en ingénieurs militaires et civils semblerait donc incorrecte. Dans le cas de la Russie, cette répartition convient d'autant moins que le terme d'« ingénieur civil » y est employé uniquement pour désigner l'ingénieur-archi-

\footnotetext{
8. Notons que le corps d'ingénieurs dépend nécessairement de l'administration concernée à titre de département, et les grades de fonction peuvent parfois servir pour dénommer les grades personnels en usage dans ce corps. Dans le cas où les structures personnelles et bureaucratiques sont difficilement repérables, nous aurons affaire à des systèmes syncrétiques. Tout ceci embrouille le tableau et crée des confusions fâcheuses dont les historiens risquent de devenir victimes. Cependant ces systèmes ont, eux-aussi, tendance à évoluer, et cette évolution va vers une répartition plus nette des fonctions entre l'administration proprement dite qui assure la gestion (y compris celle des processus de production) et les corps qui sont des organismes professionnels (comme cela s'est produit en Russie et en France aux XVIII ${ }^{\mathrm{e}}$ et XIX ${ }^{\mathrm{e}}$ siècles). En même temps, le corps n'embrasse que les ingénieurs faisant partie de l'administration, laissant en marge les fonctionnaires civils de cette dernière. Une administration peut, par ailleurs, avoir sous sa tutelle quelques corps techniques. Tel était, par exemple, le cas de la Direction générale des voies de communication russe qui, durant les années 1820-1830, avait la tutelle des organismes suivants : le Corps des ingénieurs des voies de communication (organisation élitaire au statut proche de celui de la garde), le Détachement de construction des voies de communication (organisation regroupant des techniciens dont le statut était équivalent à celui de l'armée) et les effectifs d'officiers des Brigades militaires de construction des voies de communication (de fait, officiers de l'armée qui commandaient les constructeurs organisés sur le mode militaire). On trouve à la même époque une situation analogue dans le Département du génie militaire où le Corps des ingénieurs de campagne (polevye inženery, organisation élitaire) coexistait avec celui des ingénieurs de garnison (structure au statut proche de celui du Détachement de construction des voies de communication).
} 
tecte, c'est-à-dire un spécialiste au profil particulier institutionnalisé comme métier indépendant au cours des années 1830.

Pour remédier à cette difficulté de classement, Peter Lundgreen proposa une solution originale: le classement des ingénieurs selon trois catégories: « military », « civil » (pour les ingénieurs d'État) et « civilian » (pour les ingénieurs travaillant dans l'industrie privée $)^{9}$.

Classement des corps selon leur degré de militarisation :

Les corps techniques militaires regroupaient les représentants des métiers relevant des génies militaire et maritime proprement dits (ingénieurs militaires, artilleurs, artilleurs de la marine, topographes militaires, pilotes de la flotte militaire, constructeurs de vaisseaux, etc.) et dépendaient des administrations militaires correspondantes (d'abord collèges, ensuite ministères de la Guerre et de la Marine de guerre). Les représentants des corps techniques militaires, spécialistes hautement qualifiés au statut social élevé, se voyaient attribuer les grades d'officiers de l'armée de terre et de l'armée de mer. De par leur statut, ils occupaient une position intermédiaire entre les officiers de l'armée et de la garde. Par contre, les grades d'officiers n'étaient pas nécessairement prévus pour les représentants des corps techniques inférieurs (comprenant des techniciens). La grille établie à leur égard regroupait essentiellement les divers grades de sous-officiers. Au cas où, par l'ancienneté, les techniciens accédaient aux grades d'officiers subalternes, ces derniers étaient le plus souvent corrélés avec la grille appliquée à l'armée et non pas à la garde. Notons, à titre de commentaire, que le premier grade selon la Table des rangs, celui d'enseigne, XIV classe, dans l'armée de terre et celui d'enseigne de vaisseau, XII ${ }^{\mathrm{e}}$ classe, dans la marine, donnait accès, jusqu'au milieu du XIX ${ }^{\mathrm{e}}$ siècle, à la noblesse héréditaire.

Les corps militarisés étaient organisés sur le mode militaire mais ils regroupaient, de fait, les spécialistes civils. En Russie tels furent, par exemple, le Corps des ingénieurs des voies de communication (Korpus inženerov putej soobščenija), le Détachement de construction des voies de communication (Stroitel'nyj otrjad putej soobščenija), le Corps des ingénieurs des mines (Korpus gornyh inženerov), le Corps des arpenteurs (Meževoj korpus), le Corps des forêts (Lesnoj korpus), etc. Les ingénieurs de ces corps avaient un čin et un grade militaires; toutefois une grille de grades et de fonctions de corps propres pouvait y être appliquée en parallèle (par exemple ingénieur de $1^{\text {re }}, 2^{\mathrm{e}}$ et $3^{\mathrm{e}}$ classe; directeur-conducteur des travaux; généralinspecteur, etc.). Les corps militarisés ne dépendaient pas des administrations de guerre. Ils étaient administrés par les directions ou les ministères concernés, tels que la Direction générale des voies de communication, le ministère des Finances, le ministère des Domaines, etc.

9. P. Lundgreen, « Engineering education in Europe and the U.S.A., 1750-1930 : The rise to dominance of school culture and the engineering professions », Annals of Science, 47, 1990, pp. 33-75. 
Les corps semi-militarisés et civils. Ces deux types de corps avaient ceci en commun qu'ils n'étaient pas organisés sur le mode militaire. Les grades militaires n'étaient pas appliqués (du moins pas de façon obligatoire) à leurs membres. Les spécificités qui les distinguent sont plutôt de second ordre. Les corps de la première catégorie étaient caractérisés par une discipline semi-militaire maintenue de façon rigoureuse, une hiérarchie et un système de grades propres, différents de la grille des grades civils. (Tel fut, par exemple, le cas des ingénieurs des mines avant la réforme du corps en 1834). Les corps de la deuxième catégorie se distinguaient par une organisation beaucoup plus libre ne prévoyant en tout et pour tout qu'une grille de grades civils, avec une hiérarchie et un état prévisionnel des effectifs correspondants. À partir des années 1860, tous les corps techniques non militaires ont été réorganisés selon ce principe.

Notons, pour terminer, qu'à la différence des cas précédents, le terme « corps de cadets » sera employé dans le texte uniquement pour désigner un établissement scolaire militarisé de type fermé et non pas un organisme professionnel.

\section{Genèse et développement des organisations professionnelles en Russie $\mathrm{XV}^{\mathrm{e}}-\mathrm{XVII}{ }^{\mathrm{e}}$ siècles}

Si les organisations professionnelles d'ingénieurs n'émergent en Russie qu'à l'époque des réformes de Pierre Ire, l'art de l'ingénieur pratiqué sous toutes ses formes y était, par contre, relativement développé. En même temps, le « corps de métier », forme d'organisation professionnelle très répandue en Occident, était inconnu dans la Russie moscovite ${ }^{10}$. Les débuts de la législation visant à réglementer le monopole des bourgeois à pratiquer les métiers n'apparaissent que dans la seconde moitié du XVII ${ }^{\text {e }}$ siècle, en limitant à la fois l'activité artisanale des autres

10. Cette situation n'est pas sans exceptions. Ainsi, certains auteurs mettent en évidence l'existence de structures très proches des corps de métier occidentaux dans la Russie de Kiev et de Novgorod. Dans la Russie occidentale, qui se trouvait sous la domination de la Pologne et de la Lituanie, la production artisanale était, au fond, organisée selon les mêmes principes qu'en Europe. D'ailleurs l'absence de corps de métier n'excluait pas l'apprentissage, forme de transmission des savoirs et des savoir-faire propre à l'artisanat en tant que type de production plutôt qu'à la corporation en tant qu'une des formes d'organisation de cette production. Sur les corps de métier et l'apprentissage en Russie, cf. S. V. Bahrušina, « Remeslennye učeniki v XVII v. », in Trudy Gosudarstvennogo istoričeskogo muzeja, Vyp. 3 : Razrjad obščij istoričeskij, Moscou, Izd-e GIM, 1926, pp. 101-122; I. D. Kostina, « Moskovskij Serebrjanyj rjad v pervoj četverti XVIII v.» in Trudy Vserossijskoj naučnoj konferencii «Kogda Rossija molodaja mužala s geniem Petra », posvjaščennaja 300-letnemu jubileju Otečestvennogo flota (Pereslavl'-Zalesskij, 30.6-2.7.1992 g.), 2, Pereslavl'-Zalesskij, 1992, pp. 77-90; K. A. Pažitnov, «Remeslennoe ustrojstvo v Moskovskoj Rusi i reforma Petra », Istoričeskie zapiski, 8, 1940, pp. 163-173; A. P. Pronštejn, « Organizacija novgorodskogo remesla v XVI v. », Ibid., 36, 1951, pp. 165-186; P. A. Rappoport, « Stroitel'nye arteli Drevnej Rusi i ih zakazčiki », Sovetskaja arheologija, 4, 1985, p. 80-89; K. N. Serbina, « K voprosu ob učeničestve v remesle russkogo goroda XVII veka», Ibid., 18, 1946, pp. 148-168; V. V. Stoklickaja-Tereškovič, «Problema mnogoobrazija srednevekovogo ceha na Zapade i na Rusi », Srednie veka : Sbornik, 3, 1951, pp. 74-102; E. M. Tal'man, « Remeslennoe učeničestvo Moskvy v XVII veke », Istoričeskie zapiski, 27, 1948, pp. 67-95. 
couches sociales dans les villes et le passage des bourgeois - bénéficiaires de privilèges artisanaux —, dans d'autres bourgades ou à la campagne ${ }^{11}$.

Paradoxalement, les corporations professionnelles ne se mettent définitivement en place qu'au XVIII ${ }^{\mathrm{e}}$ siècle, c'est-à-dire à l'époque où les liens féodaux sont déjà en pleine désintégration. Les unions des corps de métier qui émergent alors, en 17211722 et en 1745, sont créées à l'instigation de l'État décidé à mettre sous son contrôle fiscal et administratif l'activité des ces catégories de producteurs. La forme d'organisation professionnelle empruntée à l'Occident se révèlera donc être une coquille vide que l'État russe s'empressera de fourrer à sa guise, mais cette « farce locale » n'aura plus rien à voir avec le contenu original ${ }^{12}$.

La Russie ignorait également les corporations professionnelles organisées selon le modèle de «confréries » ou d' «ordres » - formes assez répandues dans l'Europe médiévale, telle la fameuse organisation des « Frères du Pont » fondée en France au XII ${ }^{\mathrm{e}}$ siècle par saint Bénezet ${ }^{13}$.

Les constructeurs russes ont élaboré leur forme d'organisation propre : selon la tradition ancienne ils préféraient s'organiser en artels, équipes provisoires et volatiles, donc très mobiles, qui se créaient et se dispersaient en fonction des intérêts communs et individuels de leurs membres, sans les restrictions qui étaient alors imposées aux artisans-membres des corps de métier en Occident. Ceci dit, l'artel était avant tout une unité de production et non pas un organisme destiné à enrôler les représentants d'un métier quelconque. Le fossé qui le sépare des corps techniques - formes d'encadrement professionnel des ingénieurs qui deviendront prédominantes dans la Russie du XVIII ${ }^{\mathrm{e}}$ siècle - est encore énorme.

Le premier pas dans cette direction - qui ouvre, en fait, la voie vers la modernité - s'accomplit cependant dans la deuxième moitié du Xve siècle. C'est effectivement en 1469 qu'arrive en Russie, dans le sillage de l'ambassade italienne chargée de négocier le mariage d'Ivan III avec Sophie Paléologue, l'architecte et ingénieur Anton Friazin de Bigenzu (?). Caché dans l'ombre des fiançailles princières, cet événement insignifiant en apparence marque le début d'un grand bouleversement qui changera la face du génie russe. Car Anton Friazin ${ }^{14}$ fut le premier de toute une pléiade de maîtres-constructeurs italiens (une dizaine de personnes au total) engagés au service de la Couronne entre 1469 et 1522 . Tous ingénieurs expé-

11. M. T. Beljavskij, «Soslovija i soslovnyj stroj », in Očerki russkoj kul'tury XVIII veka, Moscou, Izd-vo Moskovskogo universiteta, 1987, 2, pp.21-43, ici p. 22; P. P. Smirnov, A. N. Speranskij, «Posadskie ljudi », in Očerki istorii SSSR : Period feodalizma, XVII V., Moscou, AN SSSR, 1955, pp. 198-220.

12. M. T. Beljavskij, art. cit., p. 40; N. B. Golikova, L. G. Kisljagina, « Sistema gosudarstvennogo upravlenija », in Očerki russkoj kul'tury XVIII veka, op. cit., p. 72; A. A. Kizevetter, Posadskaja obščina v Rossii XVIII st., Moscou, 1903, pp. 145-151; Polnoe sobranie zakonov (cité infra PSZ), VI, n 3980 du 27.04.1722, pp. 664-665; S. I. Sakovič, « Social'nyj sostav moskovskih cehovyh remeslennikov 1720-h godov », Istoričeskie zapiski, 42, 1953, pp. 238261. A. N. Speranskij, Očerki po istorii Prikaza kamennyh del Moskovskogo gosudarstva, Moscou, RANION, 1930, 222 p., ici p. 207.

13. M. Čerepašinskij, Očerk istorii mostov, op. cit.(supra note 1), pp. 74-76

14. En russe du XVe siècle « Friazin » signifiait tout simplement « l'Italien ». 
rimentés, ils comptaient dans leur rang un maître dont l'excellence resta imbattable. Il s'agit d'Aristotele Rodolfo Fioravanti de Bologna (1415-1485/86?) venu en Russie en 1475 et connu surtout comme constructeur de la cathédrale de l'Assomption (1475-1479) dans les murs du Kremlin de Moscou. Or il fut également (et ce n'est pas tout!) auteur du plan général du Kremlin, chef de l'artillerie russe et directeur des travaux lors des campagnes militaires d'Ivan III' ${ }^{15}$.

15. A. V. Bunin, Istorija gradostroitel'nogo iskusstva, Moscou, Gosstrojizdat, 1953, 1, pp. 290296; A. L. Horoševič, « Dannye russkih letopisej ob Aristotele Fioravanti », Voprosy istorii, 2 , 1979, pp. 201-204; «Ioann III i Aristotel' Fioravanti », Niva, 34, 1873, pp. 529-534; V. V. Sedov, «Ital'janskij arhitektor v Pskove v XVI veke», in Arhitektura mira. Materialy konferencii «Zapad-Vostok: Vzaimodejstvie tradicii v arhitekture », Moscou, Arhitektura, 1993, 2, pp. 22-27; O. V. Tvorogov, Drevnjaja Rus'. Sobytija i ljudi, Saint-Pétersbourg, Nauka, 1994, pp. 94-95; S. M. Zemcov, « Arhitektory Moskvy vtoroj poloviny XV i pervoj poloviny XVI veka », in Zodčie Moskvy, Moscou, Moskovskij rabočij, 1981, 1, pp. 42-80; S. M. Zemcov, V. L. Glazyčev, Aristotel' Fioravanti, Moscou, Strojizdat, 1985, 184 p.; etc. La liste d'ouvrages portant sur ce sujet compte plus de 300 titres en russe, italien, français, anglais, allemand. Voir aussi : Moskva : Enciklopedija, Moscou, SE, 1980, passim.

Les origines sémantiques et la datation de l'apparition du terme « ingénieur » suscitent, à ce jour, de vives polémiques. Selon un avis assez répandu que partagent plusieurs historiens, employer ce terme en parlant des $\mathrm{XV}^{\mathrm{e}}$ et $\mathrm{XVI}^{\mathrm{e}}$ siècles serait un anachronisme puisqu'il était alors appliqué exclusivement aux militaires, «faiseurs d'engins de guerre » et de fortifications, tandis que l'ingénieur en tant que savant n'apparut que vers la fin du XVIII' siècle. Pourtant les documents de l'époque contestent cette affirmation. Citons en quatre (en respectant l'orthographe des originaux) sur les plusieurs dizaines que nous avons analysés en étudiant «la vague italienne » dans la Russie des XV e et XVI ${ }^{\mathrm{e}}$ siècles. Le premier document date du 18 juin 1438 et concerne le père ou l'oncle d'Aristote Fioravanti : «Magistros Floravantem de bolonia et micheonum de marijs, ducalles Ingignerios ». On trouve une inscription analogue du 9 septembre 1438 et une troisième, encore plus intéressante, de l'an $1440:$ : $\mathrm{M}^{\circ}$. bartholomeo fioravanti ingeniario comunis boloniae » (Tiré du Registro Visconteo di Spese, concervato alla Biblioteca Ambrosiana, 1438, fol. 25v., 69v. publié dans Luca Beltrami, Vita di Aristotile da Bologna, Bologne, Libreria Luidgi Beltrami, 1912, 130 p., ici pp. 15-17. Aristote Fioravanti, le « nôtre », se voit attribuer les mêmes titre et fonction en 1453. Dans les Memorie de Nicolo Memelini, à la date du 3 août 1455, il est mentionné comme « Maestro Aristotile di fierovanti da Bologna ingigniero Bolognexe »; de même en 1460 on l'intitule «ducali Ingeniario » (les documents respectifs sont publiés dans Ibid., p. 100; Carlo Malagola, « Del transporto della Torre di Santa Maria del Tempio in Bologna detta della Magione », Politechnico di Milano, 22, 1874, p. 203.

Ainsi, le terme d' « ingénieur » était déjà d'usage courant dans l'Italie de la première moitié du $\mathrm{XV}^{\mathrm{e}}$ siècle (et peut-être même avant), et ceci bien au-delà du domaine strictement militaire. Si la mention d' « ingénieur ducal » évoque encore les travaux de fortification, « ingénieur de Bologne » (c'està-dire de la ville de Bologne) ou « ingénieur de la commune de Bologne » est déjà bel et bien un ingénieur civil chargé des travaux publics auprès de la municipalité (ou de la commune) et payé par elle.

Parmi les compatriotes de Fioravanti venus travailler en Russie, on trouve des cas semblables. Tel Alevise le Vieux, alias Aloisio da Carezano, arrivé dans la Moscovie en 1494 : dans une lettre du secrétaire de la chancellerie ducale du 19 octobre 1496, il est désigné comme «Aluysio da Carezano magistro de muro et inzignero » (publié dans L. Beltrami, op. cit., p. 128, avec la référence aux Arch. stato Milano, et avec quelques variations insignifiantes dans S. S. Pod"japol'skij, «Ital'janskie stroitel'nye mastera v Rossii v konce XV-načale XVI veka po dannym pis'mennyh istočnikov : Opyt sostavlenija slovarja », in Restavracija $i$ arhitekturnaja arheologija. Novye materialy i issledovanija, Moscou, 1991, p. 232.

Une question se pose : s'agit-il de la profession d'ingénieur ou uniquement d'une fonction? Là aussi les documents nous éclairent, notamment le procès-verbal de la réunion Anziani di Reggio en date du 21 janvier 1463 où l'on peut lire : « Magister Aristotiles Inzignerius Illustrissimi » (publié dans L. Beltrami, op. cit., p. 83). La notion d' « ingénieur illustre » ne peut concerner que la profession.

Nous avons donc tout à fait le droit d'appeler « ingénieurs » les représentants de la « vague italienne » venus en Russie à l'époque d'Ivan III. Et ceci non seulement parce qu'ils ont exercé les fonctions propres à ce métier, mais parce que leurs pères et précepteurs d'abord, eux-mêmes ensuite, se sont identifiés à ce nom, parce qu'ils ont été désignés ainsi par leurs contemporains. 
L'activité de ces ingénieurs étrangers sur le sol russe a une double conséquence : non seulement leur influence s'est fait sentir sur l'évolution de l'architecture russe de pierre jusque dans les siècles suivants, mais leur venue même a marqué le début de la politique dite « de l'aspirateur » qui a joué un rôle décisif dans la mise en place des corps techniques d'État en Russie ${ }^{16}$.

Le pas suivant fut fait par le tsar Ivan IV (Ivan le Terrible) au milieu du $\mathrm{XVI}^{\mathrm{e}}$ siècle lorsqu'il entreprit une réforme militaire visant à consolider son pouvoir. Ainsi fut établi le règlement précisant tous les types de service militaire. Puis fut créée, entre 1545 et 1550 , une armée permanente (semi-régulière) dont les soldats sont connus dans l'histoire sous le nom générique de strel'cyl7. Cette mesure en implique une autre, très importante pour notre étude : l'introduction de grades militaires personnels fixes, premiers embryons du système ramifié et complexe de distinction professionnelle que le pays connaîtra ensuite.

Cependant un siècle et demi devra s'écouler avant que ne soit comprise et reconnue la différence essentielle entre le grade personnel (čin, ou grade honorifique) qui fixe la qualification et les mérites professionnels de l'individu, et le grade de fonction, provisoire et attribué uniquement pour la période durant laquelle l'individu assume un certain type de fonctions.

Les grades militaires européens commencent à pénétrer en Russie à travers la Pologne durant la période des Troubles. Ainsi en 1605-1606, les compagnies de gardes du corps étrangères du Faux Dimitri sont commandées par des « capitaines » (français, anglais et écossais). Les « rotmistry » apparaissent à peu près vers la même époque. Cependant les grades en nombre et variété suffisants pour former une

16. Voir à ce sujet nos travaux : D. Ju. Guzevič [Gouzévitch], Razvitie mostostroenija v Rossii v XVIII-pervoj polovine XIX veka i problemy sohranenija i ispol'zovanija tehničeskogo nasledija otečestvennyh mostostroitelej: Diss. ... kand. tehn. nauk, 3 t., Leningrad, 1990; D. Ju. Guzevič, I. D. Guzevič, Zarubežnye inženernye svjazi Rossii i plejada zabytyh imen, Leningrad, 1987, 20 p. (Manuscrit, bibl. SPF IIET RAN) ; I. Gouzévitch, «L'Institut du corps des ingénieurs des voies de communication de Saint-Pétersbourg : des modèles étrangers à l'école nationale (1809-1836) », in Formation des ingénieurs en perspective : transfert institutionnel des modèles et réseaux de médiation ( $X I X^{\mathrm{e}}-X X^{\mathrm{e}}$ ss.), Rennes, Presses Universitaires de Rennes, 2001, 20 p. (à paraître); D. Ju. Guzevič, I. D. Guzevič, Bazen Petr Petrovič (Bazain Pierre Dominique) 1786-1838, Saint-Pétersbourg, Nauka, 1992, 234 p.; 2e ed., 1995, 240 p.; Id., «Francuzskie inženery - členy Peterburgskoj Akademii nauk », in Dejateli russkoj nauki $X I X$-pervoj četverti XX vekov. Obzor literatury $i$ istočnikov, Saint-Pétersbourg, SPF IIET AN SSSR, T. I, Č. II, 1991, pp. 74-109; D. Gouzévitch, I. Gouzévitch, « Les contacts franco-russes dans le monde de l'enseignement supérieur technique et de l'art de l'ingénieur », Cahiers du Monde russe et soviétique, 34, 3, 1993, pp. 345-368 ; I. Gouzévitch, « Technical higher education in nineteenth-century Russia and France : French engineers in Russian service and Russian students in French "grandes écoles" », in ICOHTEC, 22nd International Symposium : Abstract of Papers, Bath, 1994, p. 12; Id., « Technical higher education in nineteenth-century Russia and France : Some thoughts on a historical choice », History and Technology, 12, 1995, pp. 109-117; Id., « La science sans frontières : élèves et stagiaires de l'Empire russe dans les écoles supérieures françaises au XIX ${ }^{\mathrm{e}}-\mathrm{XX}^{\mathrm{e}}$ siècles », Les Cahiers d'Histoire du CNAM, 5, février 1996, pp. 63-92.

17. Strelec (pluriel strel'cy) - arquebusier, mousquetaire. Cf. N. P. Eroškin, Očerki istorii gosudarstvennyh učreždenij dorevoljucionnoj Rossii. Posobie dlja učitelej, Moscou, Učpedgiz, 1960, pp. 5, 32-35; A. V. Černov, « Obrazovanie streleckogo vojska », Istoričeskie zapiski, 38, 1951, pp. 281-290; A. A. Zimin, « K istorii voennyh reform 50-h godov XVI v. », Ibid., 55, 1956, pp. 344-359. 
certaine hiérarchie sont importés directement de l'Europe occidentale dans les années 1630; la Russie, qui prépare alors la campagne de Smolensk, engage à son service des régiments entiers de mercenaires étrangers tout en lançant simultanément l'organisation d'unités russes selon le modèle européen. Attribués essentiellement aux étrangers, ces grades ne s'appliquent aux Russes que quelques décennies plus tard. Ainsi, le premier général russe, A. A. Šepelev, est nommé en $1667^{18}$. Cette initiative offre un des premiers exemples de la «politique de l'aspirateur» qui deviendra, à certaines époques, une dominante de la politique étrangère de la Couronne russe. Dans cette période du XVII e siècle, elle a abouti à l'émergence d'une réalité nouvelle qui n'avait pas d'antécédent à l'intérieur du pays ${ }^{19}$.

Quant aux grades proprement russes, ils étaient à l'époque d'origine très variée. Certains relevaient de l'existence de couches sociales spécifiques : les boyards, les enfants de boyards, quelques catégories de militaires - hommes de service de naissance et de recrutement (služilye ljudi ${ }^{20}$. D'autres provenaient des fonctions professionnelles exercées dans les administrations (prikaznye ljudi: d'jak, pod'jačij) ${ }^{21}$ ou à la cour (spal'nik, stol'nik, etc. $)^{22}$.

Ce bouquet hétéroclite de grades archaïques sacrés par la tradition et l'ancienneté ne formait pas, en fin de compte, un système cohérent et rationnel. Il s'est révélé parfaitement inapplicable à l'organisation de structures à hiérarchie rigide comme les corps techniques.

La réforme des administrations d'État engagée par le même Ivan IV constitue un autre pas important vers la régularisation et la structuration de la hiérarchie professionnelle à l'échelle du pays. Elle se traduit par la mise en place d'un système de prikazy ou administrations destinées à gérer, chacune dans un domaine bien précis, la vie de l'État moscovite.

En matière de génie cette innovation est vraiment révolutionnaire car elle donne naissance à une poignée d'administrations techniques organisées selon un seul et même principe et fonctionnant de façon similaire ${ }^{23}$. Certaines sont d'emblée desti-

18. S. Gabaev, V. Afanas'ev, « Voinskie zvanija v carskoj armii », Voenno-istoričeskij žurnal,9, 1940, pp. 111-115; S. V. Volkov, Russkijoficerskijkorpus, Moscou, Voenizdat, 1993, pp. 18-21.

19. Selon les estimations de S. V. Volkov, en 1696 l'armée russe comptait dans ses rangs environ 1000 officiers étrangers dont 231 dans la cavalerie et 723 dans l'infanterie, S. V. Volkov, op. cit., pp. 24,313 .

20. Služilye ljudi - militaires au service de l'État.

21. Les prikaznye ljudi peuvent être considérés comme une sous-catégorie des précédents mais ils ne sont pas militaires, cf. N. F. Demidova, « Social'naja struktura prikaznoj gruppy služilyh ljudej XVII v. », in Torgovlja, promyšlennost' i gorod v Rossii XVII-načala XIX v. Sbornik statej, Moscou, [In-t istorii SSSR AN SSSR], 1987, pp. 87-101. D’jak - secrétaire, pod'jačij - sous-secrétaire.

22. Spal'nik - chambellan de service, stol'nik - panetier.

23. Mettons bien en évidence le fait qu'il s'agit d'un système d'administrations à la différence des quelques prikazy isolés qui avaient existé auparavant, tel le Pomestnyj prikaz (administration des Bénéfices), créé à la fin du XV e siècle. A. N. Meduševskij, Utverždenie absoljutizma $v$ Rossii : Sravnitel'no-istoričeskoe issledovanie, Moscou, Tekst, 1994, p. 44 (Compte rendu par N. V. Kozlova, in Otečestvennaja istorija, 4, 1997, pp. 175-179). 
nées à gérer un domaine concret des techniques, tel le Puškarskij prikaz (administration pour la fabrication des canons et de la poudre et pour la gestion de l'artillerie; environ 1577) ${ }^{24}$ ou le Prikaz kamennyh del (administration pour les bâtiments en pierre; environ 1583/1584) ${ }^{25}$. D'autres cumulent cette fonction avec un certain nombre de responsabilités complémentaires : Sibirskij prikaz (administration pour l'aménagement de la Sibérie) ; Razrjadnyj prikaz et Novgorodskaja četvert'(pour l'artillerie et les fortifications); Pomestnyj prikaz (pour l'arpentage), etc. ${ }^{26}$. Quant au génie militaire, avant l'incendie de 1626 il relevait de la compétence du Razrjadnyj prikaz (pour les fortifications). Certains autres domaines, telles la construction et la fortification des villes, la fabrication de la poudre, la construction des ponts, etc., dépendaient de l'institut des officiers municipaux (gorodovoj prikazčik) qui se mit en place dans la deuxième moitié du XVe siècle ${ }^{27}$. L'ensemble de ces structures assurait la réalisation de travaux gigantesques menés à travers tout le pays.

Ainsi la fin du XVII siècle voit apparaître un certain nombre des conditions nécessaires pour mettre en place le système des corps techniques, organismes de l'enrôlement professionnel des ingénieurs. Parmi les facteurs décisifs trois semblent prépondérants :

- l'application consciente et systématique de la politique «de l'aspirateur » à l'échelle de l'État;

24. La première mention relative au Puškarskij prikaz date de 1577; en 1700 il est remplacé par l'Artillerijskij prikaz (administration pour l'artillerie). En 1678-1682, le Puškarskij prikaz est, de fait, intégré dans le Rejtarskij prikaz (administration des reîtres). Dans les années 16301670, la Novgorodskaja četvert' fut l'administration responsable à la fois de l'artillerie et de la fortification dans les villes du nord-ouest. Cf. G. V. Alferova, « Organizacija stroitel'stva gorodov v Russkom gosudarstve v XVI-XVII vekah », Voprosy istorii, 7, 1977, pp. 50-66; Id., «Gosudarstvennaja sistema stroitel'stva gorodov i osvoenie novyh zemel' v XVI-XVII vv. (na primere g. Kozlova i ego uezda)», Arhitekturnoe nasledstvo, 27, 1979, pp. 3-11; Id., « K voprosu o stroitel'stve gorodov v Moskovskom gosudarstve v XVI-XVII vv. », Ibid., 28, 1980; André Berelowitch, « Plaidoyer pour la noblesse moscovite. À propos des affaires d'honneur au XVII siècle », Cahiers du Monde russe et soviétique, 34, 1-2, 1993, pp. 119-138; S. K. Bogojavlenskij, «O Puškarskom prikaze », Sbornik statej v čest' Matveja Kuz'miča Ljubavskogo, Petrograd, 1917, pp. 361-385, (Voir aussi : Id., reprint, Vaduz (Liechtenstein), Europe Printing establishment, 1970) ; V. V. Kirillov, « Sibirskij prikaz i ego rol' v organizovannom stroitel'stve gorodov na novyh zemljah », Arhitekturnoe nasledstvo, 28, 1980, pp. 13-19; M. G. Miloslavskij, Istorija stroitel'noj tehniki i arhitektury, Moscou, Vysš. šk., 1964, p. 65; A. P. Pavlov, « Prikazy i prikaznaja bjurokratija (1584-1605 gg.) », Istoričeskie zapiski, 116, 1988, pp. 187-227. Selon certaines sources qui semblent quand même moins solides, le Puškarskij prikaz aurait fonctionné entre 1611 et 1706, cf. I. Fabricius, Voenno-inženernoe vedomstvo $v$ carstvovanie Imperatora Aleksandra I, Očerk I : Inženernoe upravlenie $i$ ego sredstva, Saint-Pétersbourg, 1903, pp. VIII-IX.

25. Supprimée le 18 février 1700, cette administration a été restaurée le 21 février 1705 sous le nom de Kanceljarija kamennyh del, dissoute définitivement entre juin 1707 et décembre 1708, cf. A. N. Speranskij, Očerki po istorii Prikaza kamennyh del..., op. cit. (supra note 12), pp. 201-205. Voir aussi F. Ja. Nesteruk, Vodnoe stroitel'stvo Moskvy, Moscou, Minrečflot SSSR, 1950 , p. 98.

26. Ibid. et N. P. Eroškin, Očerki istorii gosudarstvennyh učreždenij..., op. cit. (supra note 17), pp. 34-75.

27. N. P. Eroškin, op. cit., p. 14. 
- la prise de conscience de la distinction entre le grade personnel et le grade de fonction qui se manifeste au moment de l'organisation de l'armée permanente; - la naissance d'un système d'administrations techniques intégrées dans la structure bureaucratique de l'État et susceptibles de gérer des travaux de grande envergure nécessitant un personnel qualifié en nombre suffisant.

Néanmoins aucun organisme professionnel technique n'est créé ni même décidé. Pour cela, il faut attendre que le système traditionnel de gouvernement cède définitivement la place à un nouvel appareil bureaucratique d'État organisé selon le principe de la rationalité28; qu'une armée régulière de type européen et que la flotte se substituent aux troupes permanentes archaïques; que la politique « de l'aspirateur intellectuel » s'étende aussi à l'information (et pas seulement aux « cerveaux » et aux «mains » comme auparavant). Il faut ensuite attendre que soient créés des établissements scolaires spécialisés destinés à fournir auxdits corps les effectifs compétents. Il est clair que tout cela n'était possible que dans un État au pouvoir fort et très centralisé.

\section{Les premiers corps techniques à l'époque de Pierre Ier 1700-1725}

Lors des réformes de Pierre Ier toutes les structures administratives de l'État furent profondément transformées ${ }^{29}$. En 1711, la Douma des boyards fut remplacée par le Sénat. Les nouvelles organisations se substituèrent progressivement aux prikazy. En 1717-1718, ces derniers cédèrent définitivement la place aux collèges, administrations organisées selon un principe fonctionnel et non pas géographique ${ }^{30}$. Les administrations techniques et militaires y furent d'emblée très bien représentées. Sur onze collèges créés, deux furent destinés à assurer la gestion de l'industrie : le collège des Mines ${ }^{31}$ et celui des Manufactures (Berg- et Manufaktur-kollegii), tandis que deux autres : le collège Militaire et celui de l'Amirauté (Voennaja et

28. Voir A. N. Meduševskij, Utverždenie absoljutizma v Rossii ..., op. cit. (supra note 23), p. 70. Les réformes d'Ivan le Terrible visaient, elles aussi, à rationaliser le système de gouvernement, cependant elles ne sont pas allées au-delà des formes traditionnelles de l'organisation du pouvoir (pour une analyse détaillée voir L.V. Čerepnin, « Obrazovanie Russkogo centralizovannogo gosudarstva v sravnitel'no-istoričeskom aspekte (XVI-XVII vv.) », Voprosy istorii, 2, 1978, pp. 41-53).

29. Outre les travaux auxquels nous allons nous référer plus avant, voir à ce sujet M. Bogoslovskij, Petr Velikij i ego reforma, Moscou, Kooperativnoe izd-vo, 1920, pp. 91-105; W. Marshall, Peter the Great, Londres-New York, Longman, 1996, pp. 43-53; V. Mavrodin, Petr I, Moscou, Voenizdat, 1949, pp. 105-115; V. I. Lebedev, ed., Reformy Petra I. Sbornik dokumentov, Moscou, Gossocekizdat, 1937,379 p.

30. S. M. Troickij, Russkij absoljutizm i dvorjanstvo v XVIII v., Moscou, Nauka, 1974, pp. 3031; Ju. V. Kulikov, Gosudarstvennye učreždenija XVIII v., Moscou, 1956, passim (Istorija gosudarstvennyh učreždenij Rossii do Velikoj Oktjabr'skoj revoljucii, 2).

31. Le collège des Mines (Berg-kollegium) fut créé en 1720, lors de la réorganisation de l'ancienne administration des mines (plus tard des minerais) - Prikaz rudokopnyh (puis rudnyh) del, cf. Ju. H. Kopelevič, Osnovanie Peterburgskoj Akademii Nauk, Leningrad, Nauka, 1977, p. 22. 
Admiraltejskaja kollegii) se virent confier la responsabilité de l'armée et de la flotte 32 .

Outre les collèges, d'autres administrations techniques importantes voient le jour durant cette période. En premier lieu, l'Office des affaires urbaines (Kanceljarija gorodovyh del) créé en 170933 à Saint-Pétersbourg auprès de l'architecteordonnateur et «commissaire » dont le poste existait déjà auparavant. À partir de 1723, cet organisme sera connu sous le nom de Bureau du bâtiment (Kanceljarija ot stroenij) $)^{34}$.

Un autre exemple intéressant est celui de l'Office d'artillerie générale et de fortification (Kanceljarija glavnoj artillerii i fortificacii) qui se substitua en 1711 au Prikaz d'artillerie ${ }^{35}$ tout en étant placé sous la haute surveillance du grand-maître de l'artillerie, Jacob Bruce; celui-ci, à partir du 20 mai 1720, cumule cette fonction avec la responsabilité de toutes les forteresses russes. Son successeur à ce poste, nommé général-directeur de toutes les fortifications par l'ukase du 22 mai 1722, fut le général-major De Coulomb qui commandait alors la compagnie du génie de

32. Les sept autres collèges étaient : celui des Affaires étrangères (Kollegija Inostrannyh del), des Impôts (Kamer-kollegija), du Budget (Stats-kontor-kollegija), de la Révision (Revizionkollegija), du Commerce (Kommerc-kollegija), de la Justice (Justic-kollegija) et des Domaines (Votčinnaja kollegija). De fait on peut aussi considérer comme collèges le Synode (Duhovnaja kollegija) et le Magistrat principal (Glavnyj magistrat), cf. S. M. Troickij, « Ob ispol'zovanii opyta Švecii pri provedenii administrativnyh reform v Rossii v pervoj četverti XVIII veka », Voprosy istorii, 2, 1977,pp. 71-72. Le Règlement général (28 février 1720) n’en cite que dix; il ne dit rien du collège des Domaines, cf. V. I. Lebedev, ed., Reformy Petra I..., op. cit. (supra note 29), p. 108.

33. Selon d'autres données, ce nom lui a été conféré en 1706, cf. K. V. Malinovskij, « Kanceljarija ot stroenij », Leningradskaja panorama, 8, 1985, pp. 34-36; S. S. Ožegov, Tipovoe i povtornoe stroitel'stvo v Rossii v XVIII-XIX vekah, 2e éd., Moscou, Strojizdat, 1987, pp. 14, 18, 19, 210. Cette datation incertaine est à l'origine de nombreuses confusions : ainsi, certains historiens estiment que le Bureau du bâtiment fut créé durant les années 1710 ou plus tardivement encore, dans les années 1720, voir Vseobščaja istorija arhitektury, 6, [Moscou], Strojizdat, [1968], pp. 157-162.

34. La création de cet organisme est lié au nom de Le Blond (1679-1719), architecte français et haut-fonctionnaire (il avait le grade très élevé de général-architecte) du service russe. Ce Bureau fut transformé plus tard en un « vrai ministère » gérant un grand éventail de travaux d'envergure. Les meilleurs talents architecturaux et artistiques de l'époque furent concentrés en son sein. En 1727, les effectifs du Bureau s'élevaient à 2426 personnes dont 1702 spécialistes, 669 ouvriers du bataillon spécialisé qui lui fut affecté (y compris 18 officiers) et 55 fonctionnaires de l'appareil de gestion. La composition professionnelle des « spécialistes » était, elle-aussi, très variée. Outre 8 architectes ( 3 Russes et 5 étrangers), on y comptait des maîtres et des contremaîtres (le plus souvent d'origine étrangère), experts en construction d'écluses, de fontaines, de moulins et de machines diverses, mais aussi horlogers et mécaniciens. Cf. I. Kirilov, Cvetuščee sostojanie Vserossijskogo gosudarstva, v kakovoe načal, privel i ostavil neizrečennymi trudami Petr Velikij, otec Otečestva, Imperator i Samoderžec Vserossijskij i pročaja [...] sobrano trudami St. sovetnika, i byvšego v Senate obersekretarja g. Ivana Kirilova, iz podlinnejših Senatskih arhivov v fevrale mesjace 1727 g., ed. de M. Pogodin, Moscou, 1831, 1, pp. 9, 31, 32; N. Moleva, E. Beljutin, Pedagogičeskaja sistema Akademii Hudožestv XVIII veka, Moscou, Iskusstvo, 1956, p. 22; G. A. Nekrasov, « Osnovnye etapy graždanskogo, promyšlennogo i kul'turnogo stroitel'stva v Peterburge (pervaja četvert' XVIII v.) », in Promyšlennost' i torgovlja v Rossii XVII-XVIII vv., Moscou, Nauka, 1983, pp. 101118 .

35. A. Savel'ev, Istoričeskij očerk inženernogo upravlenija v Rossii, 1-3, Saint-Pétersbourg, 1879-1894. 
Saint-Pétersbourg ${ }^{36}$. C'est sur l'initiative de ce dernier que fut créé, en décembre de la même année, le Bureau du génie auprès de l'Artillerie générale (Inženernaja kontora pri Glavnoj artillerii). Cet organisme relevait encore traditionnellement de l'administration de l'artillerie ${ }^{37}$, et sa position de semi-dépendance fut maintenue jusqu'en 1726 où, par l'ukase du 25 juillet, il se vit définitivement libéré de la tutelle de l'Artillerie générale ${ }^{38}$.

Une fois mises sur pied, les administrations technico-industrielles et technico-militaires stimulèrent, à leur tour, la création des organismes d'encadrement professionnel correspondants dont les corps de l'artillerie et du génie furent les premiers fleurons. À titre d'exemple, examinons plus en détail l'histoire de l'émergence de ce dernier.

\section{Le Corps des ingénieurs du génie}

La première preuve documentaire du fonctionnement organisé des ingénieurs au sein d'une équipe particulière (osobaja komanda) est l'ukase suprême adressé au secrétaire de la Douma, Vinius, le 14 mai 1701 : le tsar y ordonne que les ingénieurs soient affectés à l'artillerie. La première mention concernant les mineurs qui avaient participé au siège de Narva date de 1700. L'année 1702 est considérée comme celle de la création de la compagnie des mineurs dont les listes conservées se rapportent à 1710. La structure des troupes du génie est définie par le statut du 8 février 1712 qui régit l'organisation de l'artillerie de campagne. Selon ce document, le régiment d'artillerie comprend, outre une compagnie de bombardiers et six compagnies de canonniers, une compagnie de mineurs et deux équipes d'ingénieurs et de pontonniers. L'ukase nominatif du 17 mars 1719 statue la création de la Compagnie du génie à Saint-Pétersbourg où sont intégrés tous les élèves de l'École du génie de Moscou. La compagnie est placée sous la responsabilité de l'ingénieurcolonel De Coulomb, comme d'ailleurs toutes les autres unités du génie ${ }^{39}$ qui passent sous sa tutelle en même temps que les forteresses conformément à l'ukase du 22 mai 1722 déjà cité.

Le document qui statue la création de la Compagnie du génie prévoit également d'autres dispositions relatives aux ingénieurs militaires et, en particulier, l'affectation de trois d'entre eux - un officier et deux ober-conducteurs - dans chaque régiment. Quoique De Coulomb dépende encore formellement du grand-maître de

36. De Coulomb passa du service français au service de la Couronne russe en 1712; S. Gabaev, V. Afanas'ev, « Voinskie zvanija... », art. cit. (supra note 18), p. XXII.

37. Cette dépendance remonte historiquement à la deuxième moitié du XVII ${ }^{\mathrm{e}}$ siècle où le Prikaz des canonniers récupéra sous son aile tous les constructeurs, fortificateurs, ingénieurs et dessinateurs russes et étrangers, anciens officiers de l'administration des Affaires étrangères (Inozemnyj prikaz) ; cf. I. Fabricius, Voenno-inženernoe vedomstvo..., op. cit. (supra note 24), pp. VIII-IX.

38. Ibid., pp. VIII-XXV.

39. Y compris la Compagnie des mines ou des mineurs (Minnaja rota) qui fusionna avec celle du génie par l'ukase du 20 mai 1723. 
l'artillerie, Jacob Bruce, ce moment peut être considéré comme décisif dans le processus de naissance du corps des ingénieurs militaires. L'état des effectifs de ce dernier, publié à la fin du règne de Pierre I ${ }^{\mathrm{er}}$, prévoyait, outre trois généraux (le lieutenant-général Münich et les généraux-majors De Coulomb et von Luberas), 12 officiers supérieurs, 67 officiers subalternes et 274 conducteurs. Le 13 janvier 1724 , les ingénieurs militaires se voient accorder le même statut que les officiersartilleurs, ces derniers étant égaux, à partir de 1714, aux officiers du régiment Preobraženskij, c'est-à-dire à la garde. Durant les mêmes années, on tente d'établir une distinction de profil entre les deux groupes d'ingénieurs militaires à l'intérieur du corps, les premiers étant les « ingénieurs de campagne « (polevye inženery) et les seconds - les « ingénieurs de garnison » (garnizonnye inženery $)^{40}$.

Le 23 mai 1727, le poste d'ober-directeur des fortifications est confié au comte Burhard von Münich ${ }^{41}$, personnage emblématique de l'histoire du génie militaire, car les quinze ans de son directorat furent une période d'indépendance et de grande effervescence pour cette administration dont le corps des ingénieurs militaires faisait partie.

Selon l'état des effectifs de l'administration du génie entériné en juin 1728, le corps des ingénieurs regroupait le régiment d'ingénieurs et la compagnie de mineurs ${ }^{42}$. Détail important pour qui veut suivre l'évolution d'une notion : on voit bien que le corps est alors perçu à la fois comme organisation professionnelle et comme unité militaire, ce qui ne sera plus le cas aux époques suivantes.

La chute de Münich, le 1er février 1742, eut des conséquences fâcheuses pour l'administration qu'il avait dirigée. Par l'ukase impérial du 15 avril 1742, les admi-

40. Cf. I. Fabricius, Voenno-inženernoe vedomstvo..., op. cit. (supra note 24), pp. XIX-XXIII; PSZ, VII, n 4412 du 13.01.1724, p. 201; D. P. Strukov, Arhiv russkoj artillerii, pod red. N. E. Brandenburga, I: 1700-1718, Saint-Pétersbourg, 1889, p. 68; P. P. Epifanov, A. A. Komarov, «Voennoe delo, armija i flot », in Očerki russkoj kul'tury XVIII veka, Moscou, Izd-vo MGU, 1987, 2, pp. 186-257.

41. Originaire d'Oldenburg, Burhard Christov von Münich (1683-1767) entra au service de la Couronne en 1721. À l'époque de l'impératrice Anna Ioanovna (durant les années 1730) il administra de fait, avec Biron et Ostermann, les affaires de l'État. Voir à son propos I. Fabricius, Voenno-inženernoe vedomstvo..., op. cit. (supra note 24); Galem, Žizn' grafa Miniha, trad. de l'allemand V. Timkovskij, 1-2, Moscou, 1806; «Diplomatičeskie dokumenty, otnosjaščiesja k istorii Rossii v XVII stoletii », in Sbornik Russkogo istoričeskogo ob-va, Saint-Pétersbourg, 1971, 6, pp. 387-407; S. N. Iskjul', « Knigi Gerharda-Antona fon Halema v Rossii », in Kniga V Rossii. Problemy istočnikovedenija i istoriografii. Sbornik naučnyh trudov, Saint-Pétersbourg, BAN, 1991, pp. 125-134; E. M. Tener et al., eds, Istorija Gosudarstva Rossijskogo. Žizneopisanija, XVIII vek, Moscou, Knižnaja palata, 1996, pp. 179-183; V. Ju. Kac, « Ešče raz ob istočnikah “Zapisok o Rossii” Manštejna (proishoždenie svedenij o pohode Miniha 1737 g.) », in Rossija V X-XVII vv. Problemy istorii i istočnikovedenija [...], Moskva, 1995, I, pp. 239-242; F. Ley, Le maréchal de Münnich et la Russie au XVIII siècle, préf. de V. L. Tapié, Paris, Plon, 1959, 319 p.; Minih, Zapiski fel'dmaršala grafa Miniha, trad. du français et ed. Subinskij, Saint-Pétersbourg, 1874, XXIX-406 p. (Zapiski inostrancev o Rossii v XVIII v., 2) ; « Minih », in Enciklopedičeskij slovar', Saint-Pétersbourg, F.A. Brokgauz, I.A. Efron, 19, 1896, pp. 368-369; [D. Guzevič], «Minih Burhard Kristof », in Sankt-Peterburg, Petrograd, Leningrad. Enciklopedičeskij spravočnik, Moscou, BRE, 1992, p. 378; Münich, maréchal de, «Ébauche » du Gouvernement de l'Empire de Russie, comment., notes de F. Ley; préf. du prince M. Shakhovskoy, Genève, Droz, 1989, 169 p.; N. N.Petruhincev, « Voinskaja komissija 1730-1732 gg.v kontekste vnutrennej politiki Anny Ioannovny », Vestnik Mosk-go un-ta, Ser. 8 : Istorija, 3, 1991, pp. 3-12.

42. I. Fabricius, Voenno-inženernoe vedomstvo..., op . cit. (supra note 24), p. XXVIII. 
nistrations de l'artillerie et du génie sont de nouveau réunies et placées sous la tutelle du grand-maître de l'artillerie et ober-directeur des fortifications, les deux postes étant alors cumulés par le landgraf Hessen-Hamburg, remplacé dans le courant de la même année par le général V. Repnin. De ce fait, le Bureau des fortifications (du génie) est redevenu une unité - relativement autonome - de l'Office de l'artillerie générale et de la fortification, et son indépendance effective a été de nouveau consacrée.

Une fois ébranlé, cet équilibre fragile s'est avéré difficile à rétablir malgré quelques efforts administratifs tentés ultérieurement, tel le Règlement de P. Šuvalov émis en 1756. Ni la scission officielle des corps du génie et de l'artillerie qu'il statue, ni la séparation des fonctions de général-ingénieur et de grand-maître de l'artillerie (general-fel'dcejhmejster) formellement égaux en rangs ne suffisent à rompre l'état de dépendance effective du génie vis-à-vis de l'administration de l'artillerie qui garde toujours, ne serait-ce qu'officieusement, sa position de force. Maintenue presque jusqu'à la fin du XVIII ${ }^{\mathrm{e}}$ siècle, cette situation de dépendance freina considérablement le développement autonome du génie militaire au sein des administrations techniques de l'État ${ }^{43}$.

Quant aux établissements techniques destinés à former les effectifs pour les corps concernés, ils apparaissent presque en même temps que les corps eux-mêmes. Les quatre écoles citées ci-dessous sont d'ailleurs pionnières de l'enseignement technique russe.

Ainsi, l'École canonnière (Puškarskaja škola), la première de la liste, fut créée à Moscou le 1er août 170144; l'École d'artillerie fut créée en 1721 à Saint-Pétersbourg, auprès du Laboratoire de pyrotechnie (Laboratornyj dom). Enfin, l'École du génie fut créée d'abord à Moscou en 1709, ensuite à Saint-Pétersbourg, le 17 mars 1719. L'histoire de ces deux établissements (qui souvent ne font qu'un) est très complexe car, réorganisés, fusionnés et séparés à plusieurs reprises, ils se présentent sous des noms différents suivant les époques et sont, de ce fait, sans cesse confondus. Pour notre étude il est important de savoir qu'à partir de 1762 ils ont fusionné au sein d'un seul et même établissement connu dans l'histoire comme le «Corps des cadets de l'artillerie et du génie ${ }^{45}$.

43. Ibid., pp. VIII-XXXV; P. P. Epifanov, A. A. Komarov, art. cit. (supra note 40); A. Savel'ev, Istoričeskij očerk inženernogo upravlenija v Rossii, op. cit. (supra note 35) ; Id., ed., Istoričeskij očerk inženernogo upravlenija v Rossii za vremja carstvovanija Imperatora Nikolaja I, Saint-Pétersbourg, 1896, XXIV-246-VI p.; G. Gabaev, Opyt kratkoj hroniki rodoslovnoj Russkih inženernyh vojsk. Posobie pri istoričeskih izyskanijah i spravkah ob inženernyh vojskah, Saint-Pétersbourg, 1907, pp. 1-3; PSZ, V, n 3330 du 17.03.1719, p. 680.

44. L'ukase concernant sa création fut émis le 10 janvier 1701; selon certaines autres sources l'école auprès du Puškarskij prikaz avait été organisée déjà en 1698.

45. I. Fabricius, Voenno-inženernoe vedomstvo..., op. cit. (supra note 24), pp. XIII-XV; P. P. Epifanov, A. A. Komarov, art. cit. (supra note 40) ; A. V. Postnikov, Razvitie kartografii i voprosy ispol'zovanija staryh kart, Moscou, Nauka, 1985, 216 p.; Doklady i prigovory, sostojavšiesja v Pravitel'stvujuščem Senate v carstvovanie Petra Velikogo, izdannye Imperatorskoju Akademieju nauk pod redakcieju N. V. Kačalova, 1 : God 1711-j, pp. 272-273 (n 383) ; 2 : God 1712-j, kniga 1-ja : janvar'-ijul', pp. 12-13, 157-158, 287-289 (n² 22, 23, 221, 394) ; V. F. Šperk, « Voenno-inženernoe obrazovanie v Rossii v XVIII veke », Vestnik Voenno-inženernoj 
Les corps de l'artillerie et du génie sont annexés aux armes techniques. La troisième arme technique, apparue en Russie à l'époque de Pierre Ier, fut la flotte militaire. Pour cette raison nous avons tendance à considérer le corps des officiers de marine comme un nouveau corps technique.

Comme dans les cas précédents, la formation des cadres navals est assurée par des écoles fondées à peu près à la même époque que le corps lui-même : il s'agit de la fameuse École de navigation, ouverte à Moscou par l'ukase du 14 janvier 170146, et de l'Académie maritime (ou Académie de la garde de la marine - Akademia morskoj gvardii), inaugurée à Saint-Pétersbourg par l'ukase du 1er octobre 1715. Parmi les disciplines enseignées dans cette dernière figurent les mathématiques, la navigation, la géodésie, l'astronomie, le dessin, l'artillerie, la fortification, les architectures civile et navale ${ }^{47}$. La formation des officiers de marine était donc très performante pour l'époque.

L'année 1715 voit apparaître les premiers grades de l'artillerie maritime (cejhmejster, fejerverker-kapitan, etc.). Deux décennies plus tard, en 1734, le Corps de l'artillerie maritime devient une unité autonome ${ }^{48}$.

Le groupe professionnel des constructeurs de vaisseaux se dote, lui aussi, à cette époque d'une grille de grades/rangs technico-militaires spéciaux (sarvajerskie

akademii RKKA im. V.V. Kujbyševa. Jubilejnyj sbornik : 120 let Voenno-inženernoj akademii RKKA 1819-1939, Moscou, Izd-vo VIA RKKA, 1939, pp. 51-70; V. N. Sokol'skij, « Iz istorii porohovyh raket (XVII-XIX vv.) », Trudy IIET AN SSSR, 45 (Istorija mašinostroenija), Moscou, 1962, p. 51; A. V. Postnikov, Razvitie krupnomasštabnoj kartografii v Rossii, Moscou, Nauka, 1989, p. 35.

46. Selon certains autres auteurs, elle fut ouverte le 19 août 1699.

47. I. Fabricius, Voenno-inženernoe vedomstvo..., op. cit. (supra note 24), p. XI; Ju. H. Kopelevič, op. cit. (supra not 31), pp. 23-24; P. P. Epifanov, A. A. Komarov, art. cit. (supra note 40) ; A. V. Postnikov, Razvitie krupnomasštabnoj kartografii..., op. cit. (supra note 45), pp. 3637; N. I. Barbašev, K istorii morehodnogo obrazovanija v Rossii, Moscou, Izd-vo AN SSSR, 1959, pp. 1-104; V. N. Berh, Žizneopisanija pervyh rossijskih admiralov ili opyt istorii rossijskogo flota, Saint-Pétersbourg, 1831, 1, pp. 44-45; A. P. Denisov, Leontij Filippovič Magnickij, Moscou, Prosveščenie, 1967, 143 p.; I. Ja. Depman, «Leontij Filippovič Magnickij », Matematika v škole, 5, 1940, pp. 18-23; D. D. Galanin, L.F. Magnickij i ego arifmetika, 2 t., Moscou, 1914; N. A. Konstantinov, E. N. Medynskij, M. F. Sabaev, Istorija pedagogiki, 4e ed., Moscou, Prosveščenie, 1974, pp. 164-165; N. A. Konstantinov, V. Ja. Struminskij, Očerki po istorii načal'nogo obrazovanija $v$ Rossii, 2e ed., Moscou, Učpedgiz, 1955, p. 39; A. M. Larionov, Istorija Instituta inženerov putej soobščenija Aleksandra I za pervoe stoletie ego suščestvovanija 1810-1910, Saint-Pétersbourg, 1910, pp.4-6; V.P. Mitrofanov, P.S. Mitrofanov, Školy pod parusami : Učebnyj parusnyj flot XVIII-XIX VV., Leningrad, Sudostroenie, 1989, pp. 22-26; K.-K., « Morskoj kadetskij korpus », in Enciklopedičeskij slovar', Saint-Pétersbourg, F. A. Brokgauz, I. A. Efron, 1896, 19a, pp. 906-907; PSZ, V, nº 2937 du 1.10.1715, pp. 173-176; V. E. Prudnikov, « Pervyj russkij arifmetik i geometr (K 250-letiju so dnja publikacii “Arifmetiki” L. F. Magnickogo) », Matematika v škole, 2, 1953, pp. 12-15; V. K. Sergeev, « Moskovskaja Matematiko-Navigackaja škola », Voprosy geografii, 34 (Kartografija), Moscou, 1954, pp. 150-160; A. E. Suknovalov, «Pervaja v Rossii voenno-morskaja škola », Istoričeskie zapiski, 42, 1953, pp. 301-306; Id., « Čemu i kak obučali v peterburgskoj Morskoj akademii pri Petre I (Iz istorii školy v Rossii XVIII veka)», Učenye zapiski Leningradskogo gosudarstvennogo pedagogičeskogo instituta, istoričeskij fakul'tet, 13, 2, 1956, pp. 123-144; F. Veselago, Očerk istorii Morskogo kadetskogo korpusa, Saint-Petersbourg, 1852, 208-144 p. Voir aussi V. E. Prudnikov, Russkie pedagogi-matematiki XVIII v. Posobie dlja učitelej, Moscou, Gosučpedizdat Minpros RSFSR, 1956, 640 p.

48. S. V. Volkov, op. cit. (supra note 18), p. 48; PSZ, XLI, nº 6568 du 22.04.1734, p. 198. 
činy). Selon le Règlement de 1720 l'ober-sarvajer avait le rang de capitainecommandeur ( $5^{\mathrm{e}}$ classe selon la Table des rangs), le maître-charpentier - celui de capitaine de $3^{\mathrm{e}}$ rang, etc. ${ }^{49}$. Cependant, l'existence de grades techniques hiérarchisés n'a pas donné lieu cette fois à l'émergence du corps technique correspondant. Au contraire, à partir de 1732, les constructeurs de vaisseaux perdent tous leurs acquis et doivent se contenter des grades en usage dans l'armée ${ }^{50}$. De sorte que la question d'une organisation indépendante pour les représentants de ce groupe professionnel ne se pose même plus tout au long du XVIII ${ }^{\mathrm{e}}$ siècle.

\section{La Table des rangs}

La fameuse Table des rangs, entrée en vigueur le 24 janvier 1722, est un document constitutif unique en son genre dont on ne doit pas sous-estimer l'importance pour l'histoire de la bureaucratie russe. Toute l'activité réformatrice de Pierre Iren en matière d'administration civile, militaire et judiciaire s'y trouve condensée, synthétisée et formalisée à l'échelle de l'État. Selon la caractéristique que lui a donné l'historien A. N. Meduševskij, « elle représentait une loi sur le régime du service d'État qui marquait la rupture avec la tradition précédente, patriarcale, de l'administration. [...] L'importance historique principale de la Table consistait en ce qu'elle avait rationalisé [...] le service administratif : le principe fondamental du classement hiérarchique (des činy) appliqué à la structurer était celui de l'aptitude au service et non pas celui des origines ${ }^{51}$. Cela conférait à l'élite dirigeante un surplus de mobilité dû au fait que l'attribution des titres de noblesse par le monarque dépendait directement de l'ancienneté dans le service. La Table était donc un système hiérarchique bien réglementé où les grades et les fonctions étaient répartis en 14 classes ou rangs. Le rang acquis par l'individu lui était attribué à vie ${ }^{52}$. Un État

49. S. V. Volkov, op. cit.(supra note 18), p. 49.

50. Ibid.

51. A. N. Meduševskij, Utverždenie absoljutizma v Rossii ..., op. cit. (supra note 23), p. 54.

52. Sur les rangs dans l'ancienne Russie, sur les réformes de Pierre Ir dans ce domaine et sur les rapports établis entre la noblesse et la bureaucratie, voir les documents cités supra note 29; voir aussi : I. Ju. Ajrapetjan, «Stol'niki kak odna iz kategorij feodal'noj aristokratii v 80-h gg. XVII v. (po materialam bojarskih spiskov)», Vestnik Moskovskogo un-ta, ser. 8 : Istorija, 6, 1980, pp. 67-80; S. K. Bogojavlenskij, « Prikaznye d'jaki XVII veka », Istoričeskie zapiski, 1, 1937, pp. 220-239; S. K. Bogojavlenskij, « Vooruženie russkih vojsk XVI-XVII vv. », Ibid., 4, 1938, pp. 258-283; Bojarskie spiski poslednej četverti XVI-načala XVII V. i rospis' russkogo vojska 1604 g., Moskva, 1979, 1, 341 p. (compte rendu in Istorija SSSR, 50, 1980, pp. 204206) ; Gosudarstvennaja služba v Rossii. Opyt organizacii i kadrovogo obespečenija, Nižnij Novgorod, "Nižnij-Novgorod", 1994, 213 p.; M. Confino, « À propos de la notion de service dans la noblesse russe aux XVIII e et XIX ${ }^{\mathrm{e}}$ siècles », Cahiers du Monde russe et soviétique, 34, 1-2, 1993, pp. 47-58 ; J. P. Le Donne, « The eighteenth-century Russian nobility : Bureaucracy or ruling class? », Ibid., pp. 139-148; M. Raeff, « La noblesse et le discours politique sous le règne le Pierre le Grand », Ibid., pp. 33-46; R. G. Skrynnikov, « Glavnye vehi razvitija russkogo dvorjanstva v XVI-načale XVII vv. », Ibid., pp. 89-106; A. K. Levykin, « Russkie gorodovye puškari vtoroj poloviny XVII v. », Voprosy istorii, 3, 1985, pp. 176-180; V. V. Mavrodin, Roždenie novoj Rossii, Leningrad, izd-vo Leningradskogo un-ta, 1988, pp. 140-151; 
régulier avait besoin d'un appareil exécutif idéal fonctionnant selon ses règlements et ses instructions ${ }^{53}$.

La rationalité des principes d'avancement établis par la Table se voit confirmée par le fait que, malgré nombre de corrections apportées ultérieurement, elle resta, au fond, intacte jusqu'en 1917.

Initialement la Table comprenait trois types de grades : militaires, civils (d'État ou statskie) et de la Cour. Les grades militaires étaient, à leur tour, répartis en grades de l'armée, de la garde, de l'artillerie (les grades d'ingénieur figurant dans cette même colonne) et de la marine ${ }^{54}$, la priorité étant accordée au service militaire.

Vers le milieu du XVIII ${ }^{\mathrm{e}}$ siècle, les rangs se voient regroupés un peu différemment : chacun est dorénavant reparti en cinq types de čin suivant cinq domaines de service possibles : militaire, civil, de la marine militaire, de la cour et des mines. Les différences entre les činy existant dans les différentes armes à l'intérieur de l'armée de terre n'allaient pas au-delà du groupe des činy militaires proprement dits.

Les grades personnels des mines - en raison de leur émergence plus tardive et de leur disparition plus précoce - sont devenus une vraie pierre d'achoppement pour les historiens. Ainsi l'abondante littérature consacrée aux činy, grades et titres dans la Russie ancienne ou bien les ignore ou bien les effleure vaguement ${ }^{55}$. Cepen-

151; A. N. Meduševskij, « Rossijskoe gosudarstvo XVII-XVIII vekov v osveščenii sovremennoj nemarksistskoj istoriografii. Obzor literatury », Istorija SSSR, 3, 1988, pp. 195-206; S. G. Puškarev, Obzor russkoj istorii, 3e ed., Moscou, Nauka, 1991, pp. 204-206, 234-237; V. Ju. Rikman, Dvorjanskoe zakonodatel'stvo Rossijskoj imperii, Moscou, Gerol'dija, 1992, 119 p.; N. Zagoskin, Očerki organizacii i proishoždenija služilogo soslovija v do-petrovskoj Rusi, Kazan', 1875, 221 p.; E. S. Zevakin, « Pod'jačie Pomestnogo prikaza načala XVIII v. (Po “skaskam" 1706-1709 gg.) », Istoričeskie zapiski, 11, 1941, pp. 280-283; A. A. Zimin, « O sostave dvorcovyh učreždenij russkogo gosudarstva konca XV i XVI v. », Ibid., 63, 1958, pp. 180205; Id., « D'jačeskij apparat v Rossii vtoroj poloviny XV-pervoj treti XVI v. », Ibid., 87, 1971, pp. 219-286; V. A. Evreinov, Graždanskoe činoproizvodstvo v Rossii, Saint-Pétersbourg, 1887, pp. 7-25, 71-74 (Istoričeskij vestnik, 30, 1887, supplément). Un survol analytique de seize ouvrages anglophones consacrés à la bureaucratie russe des différentes périodes a été fait par Ronald Grigor Suny, « Rehabilitating tsarism : The Imperial Russian state and its historians : A review article », Comparative Studies in Society and History. An International Quarterly, 31, 1989, pp. 168-179.

53. A. N. Meduševskij, Utverždenie absoljutizma v Rossii..., op. cit. (supra note 23), p. 52.

54. PSZ, VI, n 3890 du 24.01.1722 (Tabel' o rangah vseh činov [...]), pp. 486-493.

55. Voir, par exemple, sur ce sujet A. N. Meduševskij, Utverždenie absoljutizma v Rossii ..., op. cit. (supra note 23), p. 52; V. A. Evreinov, Graždanskoe činoproizvodstvo v Rossii, op. cit. (supra note 52) ; A. K. Stas', Rossijskaja istoričeskaja mozaika. Činy, tituly i zvanija Rossijskoj imperii, [Moscou], NIC "SNIIP”, 1992, 48 p.; « Činovničestvo », in BSE, 3e ed., Moscou, SE, 1978, 29, pp. 206-208; " Činy, zvanija i tituly v Rossii », in Sovetskaja istoričeskaja enciklopedija, Moscou, SE, 1976, 16, pp. 52-59; E. P. Karnovič, Rodovye prozvanija i tituly V Rossii, Slijanie inozemcev s russkimi, Saint-Pétersbourg, Izd-vo MFIN, 1991, 104 p. (1 $1^{\text {re }}$ ed. : Saint-Pétersbourg, 1886) ; P. Kovalev, Ustrojstvo gosudarstva Rossijskogo, Leningrad, Gidrometeoizdat, 1991, 55 p.; M. V. Kukel', Tabel' o rangah voennyh, graždanskih i pridvornyh činov Rossijskoj imperii, [S.1., 1992], 15 p.; Kurs statistiki Rossijskogo gosudarstva. Sostavlen dlja Instituta Korpusa Inženerov putej soobščenija, [Saint-Pétersbourg, 1840], pp. 40-41 (Litogr. izd.) ; Otryvki iz zapisok L. N. Engel'gardta, Weimar, Druck von G. Uschmann, [pas 
dant, ce peu d'attention de la part des historiens ne diminue en rien l'importance implicite de ce sujet pour notre recherche, car il témoigne à sa façon des efforts incessants déployés par l'État russe en quête de formes appropriées pour encadrer ses ingénieurs.

La tâche était difficile et l'élaboration de la Table a exigé un effort de synthèse énorme : plus de deux dizaines de textes - règlements officiels ou documents récapitulatifs officieux concernant les systèmes de grades - ont été recueillis par voie diplomatique dans nombre de pays européens ${ }^{56}$ tels que l'Angleterre, la Prusse, la Suède, le Danemark, la France, l'Autriche, Venise, la Turquie, l'Espagne, la Saxe, la Hollande, Gênes et la Pologne ${ }^{57}$.

avant] 1881, p. 111; V. Volžskij, « Tovarišč tituljarnyj sekretar' », Nedelja, 2, 1995, p. 13; A. Kizevetter, « Tabel' o rangah », in Enciklopedičeskij slovar', Saint-Pétersbourg, F. A. Brokgauz, I. A. Efron, 1901, 32 (d/t. 63), p. 439-444; et S. M. Troickij, Russkij absoljutizm i dvorjanstvo ..., op. cit. (supra note 30), pp. 104, 109, 150; L. E. Šepelev, Tituly, mundiry, ordena v Rossijskoj imperii, Leningrad, Nauka, 1991, 225 p., ici p. 93; D. I. Raskin, « Činy i gosudarstvennaja služba v Rossii v XIX-nač. XX vv. », in Russkie pisateli 1800-1917. Biografičeskij slovar', Moscou, SE, 1989, 1, pp.601-603; N. I. Pavlenko, «U istokov rossijskoj bjurokratii », Voprosy istorii, 12, 1989, pp. 3-17; V. Ju. Rikman, Dvorjanskoe zakonodatel'stvo Rossijskoj imperii, Moscou, Gerol'dija, 1992, 119 p.; L. E. Šepelev, Otmenennye istoriej : činy, zvanija i tituly v Rossijskoj imperii, Leningrad, Nauka, 1977, passim (compte rendu : A. P. Korelin, Istorija SSSR, 2, 1979, pp. 185-187) ; S. M. Troickij, « Iz istorii sozdanija tabeli o rangah », Istorija SSSR, 1, 1974, pp.98-111; V. Virginskij, Tvorcy novoj tehniki v krepostnoj Rossii, 2e ed., Moscou, 1962, pp. 376-377. Voir aussi les documents cités supra dans la note 29.

56. Étant donné que cet article traite de l'histoire administrative, nous avons sciemment laissé de côté les problèmes du transfert du savoir technique proprement dit, y compris au cours de la Grande Ambassade (1697-1698). C'est en effet un sujet à part auquel les auteurs prêtent une attention plus particulière dans d'autres travaux. Un aspect peu étudié de cette énorme opération de transfert a été, notamment, traité dans l'article consacré à l'histoire de l'espionnage technique, cf. D. Gouzévitch, I. Gouzévitch, "Le phénomène des "ingénieurs-résidents" : reconnaissance légale ou espionnage technique? », Cahiers d'Histoire de la Philosophie des Sciences, 47 (De la diffusion des sciences à l'espionnage industriel $X V^{\mathrm{e}}-X X^{\mathrm{e}}$ siècle : Actes du colloque de Lyon (30-31 mai 1996) de la Société française d'histoire des techniques, éd. par A. Guillerme), 1999, pp. 159-181. Voir aussi I. Gouzévitch, Le transfert du savoir technique et scientifique et la construction de l'État russe : fin $X V^{e}$-début $X I X^{e}$, Thèse, Université de Paris VIII, dir. André Guillerme, 2001, 3 t.

57. Certains éléments puisés dans les différents systèmes nationaux ont été effectivement utilisés lors de l'élaboration de la Table : ainsi le système danois a été pris en compte pour la répartition des činy selon les rangs, tandis que le système prussien à été appliqué à la rédaction des commentaires. Cf. A. N. Meduševskij, Utverždenie absoljutizma v Rossii..., op. cit. (supra note 23), pp. 195-196; S. M. Troickij, Russkij absoljutizm..., op. cit. (supra note 30), p. 29. Viennent ensuite les systèmes français (le féminin du mot «Table », assez peu usité en russe, n'en est-il pas le témoignage?) et suédois. Certains auteurs, tel S. Troickij, accordent d'ailleurs à l'influence suédoise une place beaucoup plus importante, Ibid.,pp. 59-61,71; S. M. Troickij, « Ob ispol'zovanii opyta Švecii... », art. cit. (supra note 32). Un point dans cette hypothèse semble effectivement incontestable : la législation suédoise en tant que telle (et la doctrine caméraliste qui est à l'origine de la structure de son État en particulier) a eu un très grand impact sur la législation russe. Elle a été utilisée notamment lors de la création des collèges ou lors de l'élaboration du projet du Code de 1720-1725. Cf. E. Anisimov " "Švedskaja model"” s russkoj "osobost'ju” : Reforma vlasti i upravlenija pri Petre Velikom », Zvezda, 1, 1995, pp. 133-149; A. G. Man'kov, « Ispol'zovanie v Rossii švedskogo zakonodatel'stva pri sostavlenii proekta Uloženija 1720-1725 gg. », in Istoričeskie svjazi Skandinavii i Rossii XI-XX vv., Leningrad, 1970, pp. 112-126; A. N. Meduševskij, Reformy Petra I i sud'by Rossii. Naučno-analitičeskij obzor, Moskva, INION, 1994, 55 p.; 
Résultat de l'analyse comparée des documents recueillis, la Table des rangs russe se présente en quelque sorte comme la quintessence de l'expérience accumulée par divers pays européens en matière d'administration ${ }^{58}$. Elle comporte, formulés de la façon claire et laconique, les principes rationnels de l'organisation et du fonctionnement de la bureaucratie dans les conditions d'un État absolutiste; elle témoigne également, de manière conséquente, du rejet décidé des formes traditionnelles (patriarcales) du pouvoir et de la gestion; elle statue, enfin, la séparation décisive des services militaire, civil et de la Cour tout en dissociant le rang personnel (classe) de la fonction ${ }^{59}$.

La Table fut le fruit d'un travail collectif. Le monarque en personne prit la part la plus active dans son élaboration et dans sa rédaction; la première version sortit de la plume d'A. I. Ostermann; J. Bruce y apporta son énorme énergie et son expérience en y ajoutant les grades du Berg-Collège. Le rôle de Bruce est traditionnellement mis en avant par les historiens. Il est pourtant tout à fait comparable à l'activité des dizaines d'autres sénateurs, membres des Collèges militaire et de l'Amirauté ou diplomates qui avaient participé aux débats préalables. La liste des acteurs du projet

G. A. Nekrasov, « Učreždenie kollegij v Rossii i švedskoe zakonodatel'stvo », in Obščestvo i gosudarstvo feodal'noj Rossii, Moscou, Nauka, 1975, pp. 334-343; C. Peterson, Peter the Great's administrative and judicial reforms : Swedish antecedents and the process of reception, Stockholm, A.B. Nordiska Bokhandeln, 1979, X-448 p. (aimablement communiqué par Marc Raeff).

58. Le Statut maritime de 1720 a été élaboré apparemment de façon analogue. Les auteurs du XIX ${ }^{\mathrm{e}}$ siècle (Vesselago, Mel'nickij et autres) estimaient qu'il était issu de l'analyse d'un certain nombre de statuts européens. Malheureusement, cette question n'a pas eu son Meduševskij, et les historiens qui l'ont étudiée dans les années 1950 (comme G. Sal'man) se sont efforcés de nier le rôle de toute influence étrangère. G. Ja. Sal'man, « Morskoj ustav $1720 \mathrm{~g}$. - Pervyj svod zakonov russkogo flota », Istoričeskie zapiski, 53, 1955, pp. 310-321. Hélas, cette position, très avantageuse dès que la lutte pour la priorité est engagée, s'applique mal à la mise en évidence des réalités historiques.

59. Il faut tenir compte du fait que la Table (version 1722) ne prévoyait cette séparation qu'à l'égard du rang (classe personnelle) de chaque fonctionnaire (du $1^{\mathrm{er}}$ au $14 \mathrm{e}$ ) et de l'éventail de fonctions qu'il pouvait occuper à ce titre. Quant à la dénomination de cette classe dans chaque service (c'est-à-dire non seulement le numéro d'ordre dans la hiérarchie générale, mais aussi le grade ou la dénomination du čin), la séparation n'a été suivie de façon conséquente qu'à l'égard du service militaire. Pour qu'elle s'étendît au domaine du service civil, qui venait d'être créé, il fallait beaucoup plus de temps, et encore il ne s'agissait que de la séparation de quelques dénominations de fonction réussies qui, en se dissociant de la fonction même ont été reliées à la classe (rang) en tant que telle. Ainsi, après la suppression des collèges au début du XIXe siècle, tous les grades de collège (kolležskie činy) se sont transformés en un système de signes conventionnels et ont été maintenus uniquement en qualité de dénominatifs de čin (grade personnel) (par exemple, greffier de collège $-14^{\mathrm{e}}$ classe ; secrétaire de collège $-10^{\mathrm{e}}$ classe ; assesseur de collège $-8^{\mathrm{e}}$ classe; conseiller de collège $-6^{\mathrm{e}}$ classe). Citons également quatre exceptions à cette règle. La Table (version 1722) comportait déjà les grades de conseiller secret actuel ( $2^{\mathrm{e}}$ classe) et de conseiller secret ( $4^{\mathrm{e}}$ classe, puis, à partir du mai $1724-3^{\mathrm{e}}$ classe) qui ne correspondaient à aucune fonction : c'étaient des činy/grades à l'état pur. Par l'ukase du 7 mai 1724, Pierre Irr leur adjoint deux autres činy/grades analogues - ceux de conseiller d'État actuel (4e classe) et de conseiller actuel (5e classe). S. M. Troickij, Russkij absoljutizm..., op. cit. (supra note 30), p. 120; Id., « Ob ispol'zovanii opyta Švecii... », art. cit. (supra note 32), pp. 32-34. L'autonomie du rang de la Table en tant que čin personnel a été définitivement fixée par la loi plus tardivement - sous le règne de Catherine II $(1767,1790)$ puis de Paul Ier. V. A. Evreinov, Graždanskoe činoproizvodstvo v Rossii..., op. cit. (supra note 52), pp. 40-41. 
ne serait pas complète sans citer Leibniz, alors au service de la Couronne, dont le rôle d'initiateur fut certainement important au tout début ${ }^{60}$.

Quels sont donc les traits typiques que la Table des rangs confère à l'organisation corporative des ingénieurs en Russie? En premier lieu, c'est l'opportunité réelle de changer d'état et de parvenir à l'élite dirigeante grâce à la formation et aux compétences professionnelles acquises, mais aussi grâce aux mérites personnels et à l'ardeur dans le service ${ }^{61}$. Les privilèges accordés s'étendaient également aux descendants ${ }^{62}$. L'analyse des parcours professionnels d'un grand nombre de spécialistes démontre de façon convaincante que tous les ingénieurs quelque peu connus ayant fait un service suffisamment long ont pu accéder au grade de général, c'est-àdire passer dans les rangs de «l'élite dans l'élite » ${ }^{63}$. Tout ceci rendait le travail intellectuel suffisamment prestigieux et donc attrayant à l'échelle du pays.

\section{Les corps d'ingénieurs en Russie, 1750-1810}

Le premier tiers du XVIII siècle s'acheva par la mise en place de quatre corps techniques militaires. Ils correspondaient, de façon générale, aux domaines d'acti-

60. S. Gabaev, V. Afanas'ev, « Voinskie zvanija v carskoj armii », art. cit. (supra note 18), p. 115; A. N. Meduševskij, Utverždenie absoljutizma $v$ Rossii..., op. cit. (supra note 23), p. 204; S. M. Troickij, Russkij absoljutizm..., op. cit. (supra note 30), pp. 48-118; A. K. Stas', Rossijskaja istoričeskaja mozaika..., op. cit. (supra note 55), p. 5; A. Kizevetter, « Tabel' o rangah », art. cit. (supra note 55).

61. Ainsi, le Règlement du Corps des hydrauliciens (lequel d'ailleurs n'a jamais été créé) indique clairement : «Les constructeurs hydrauliques ou hydrauliciens peuvent s'attendre à être avancés en grades non seulement par leur ancienneté au service : outre cela, ils seront distingués et récompensés en fonction de l'excellence de leurs travaux et des services utiles qu'ils rendent à l'État ». $P S Z, X X I, n^{\circ} 15562$ du 27.10.1782,p. 718; n 15563 du 31.10.1782.,p. 719. Le droit à toutes sortes de privilèges accordé aux personnes ayant reçu une formation correspondante est dû à Pierre Irer. Or sa formalisation définitive date de 1731, époque où B. Münich lance la création du Corps des cadets nobles (Šljahetskij kadetskij korpus). Le statut de ce dernier a servi «d'exemple des privilèges octroyés aux élèves des autres établissements scolaires ». V. A. Evreinov, Graždanskoe činoproizvodstvo v Rossii, op. cit. (supra note 52), p. 38. Ce point est d'une importance extrême pour notre étude.

Un autre corps technique, celui des topographes militaires, créé en 1822, offre un exemple éclatant du fonctionnement de ce mécanisme qui assurait la passage à l'état de la noblesse des techniciens doués (issus de différents états) en fonction de leurs connaissances et de leur ancienneté dans le service. Ce corps puisait ses effectifs parmi les « cantonistes » (enfants de troupe et pupilles des orphelinats militaires) formés à l'École des topographes militaires, établissement technique de niveau secondaire. Après 12 ans de service irréprochable dans les grades de sous-officiers, ils se voyaient attribuer les činy d'officiers du corps qui leur donnaient automatiquement accès aux titres de la noblesse héréditaire. Un examen spécifique de contrôle des connaissances permettait de réduire ce délai à 8 ans. Z. K. Novokšanova, Fedor Fedorovič Šubert, voennyj geodezist, Moscou, Geodezizdat, 1958, pp. 16-20.

62. N'importe quel grade de sous-officier donnait alors accès à la noblesse héréditaire, ce droit avait été fixé par la loi une année avant l'entrée en vigueur de la Table. PSZ, VI, n 3705 du 16.01.1721 (O vydače Ober-Oficeram na dvorjanstvo patentov), p. 290. Notons que les grades civils inférieurs inclus dans la Table ne donnaient accès qu'à la noblesse personnelle.

63. D. Ju. Guzevič, Razvitie mostostroenija v Rossii..., op. cit. (supra note 16), 2, pp. 52, 5657; D. Ju. Guzevič, I. D. Guzevič, Zarubežnye inženernye svjazi Rossii..., op. cit. (supra note 16). 
vité technique et scientifique privilégiés à l'époque de Pierre ${ }^{\mathrm{e}}$. Cependant, au fur et à mesure que l'industrie et l'art de l'ingénieur se développaient, d'autres branches devenaient prioritaires. La nécessité d'organiser professionnellement les groupes d'ingénieurs qui agissaient sans liens directs avec les forces armées s'imposait.

La recherche de formes d'organisation optimales répondant, de plus, aux spécificités de chaque groupe concerné s'avéra longue, difficile et quelque peu confuse. On procédait par tâtonnement, en explorant des voies et des méthodes variées, parfois contradictoires et peu appropriées. En fin de compte, quatre directions essentielles se profilèrent, et nous pouvons constater que la plupart des corps créés dans la deuxième moitié du XVIII ${ }^{\mathrm{e}}$ siècle furent organisés selon l'une des modalités suivantes : - la formation du corps dite « rampante »; - la formation du corps « de facto »;- la militarisation directe; - le dualisme militaro-civil.

\section{La formation « rampante »}

Cette possibilité était implicitement offerte par la Table des rangs elle-même. Rappelons-nous que sa première version réglementait déjà quatre types de grades militaires, avec des grilles spéciales pour la marine et l'artillerie. Les grades d'ingénieurs étaient inclus dans la colonne de cette dernière (ce qui témoignait, d'ailleurs, de leur position dépendante en 1722) : ainsi, le grade de « colonel d'artillerie » était supérieur en rang à celui de «colonel-ingénieur » ( $5^{\mathrm{e}}$ et $6^{\mathrm{e}}$ classe respectivement $)$. La première direction consistait donc à créer, pour chaque nouveau corps technique (ou pour un groupe de corps), comme pour une arme nouvelle, un système de grades à part et une colonne spéciale dans la Table des rangs de l'État.

Une procédure très lourde, certes, mais susceptible de mener droit au but. L'expérience tentée par l'Administration des mines en est la meilleure preuve. La grille spécifique de grades qu'elle a mis progressivement en place fut empruntée au système saxon ${ }^{64}$. Étant de jure une variation des grades civils, les grades des mines

64. Les premiers grades des mines (činy ot Berg-Kollegii - qui étaient en même temps des fonctions) furent introduits dans la Table par J. Bruce deux jours avant l'approbation de cette dernière et ils parurent dans sa première version : ober-bergmejster $\left(8^{\mathrm{e}} \mathrm{cl}.\right)$, berg-mejster et ober-berg-probirer ( $9^{\mathrm{e}} \mathrm{cl}$.), markšejder (12 el cl.), etc. S. M. Troickij, Russkij absoljutizm..., op. cit. (supra note 30), pp. 104, 109; V. A. Evreinov, Graždanskoe činoproizvodstvo v Rossii, op. cit. (supra note 52), pp. 78-82; PSZ, VI, n 3890, du 24.01.1722, pp. 486-493. Au cours des 45 années suivantes, neuf autres grades de l'Administration des mines furent introduits dans la Table. S. M. Troickij, Ibid., p. 150. L'initiative en revint à V. de Gennin qui, en 1731, avait proposé la grille des grades des mines pour les employés des forges afin qu'ils bénéficient des mêmes rangs et des mêmes appointements que les ingénieurs militaires. Gennin utilisa pour sa grille les dénominations des grades saxes. Tatiščev, envoyé en 1734 dans l'Oural avec mission de contrôle, y apporta quelques changements. Ainsi il posa des limites à l'anoblissement des contremaîtres et essaya (d'ailleurs sans succès) de russifier les dénominations des grades. La «Table des grades des personnels des forges sibériennes » (Štat činov pri sibirskih gornyh zavodah) qu'il rédigea fut approuvée le 2 octobre 1734. L. A. Daškevič, « Social'no-pravovoe položenie tehničeskih kadrov gornyh zavodov Urala v pervoj polovine XIX v. », in Vlast', pravo i narod na Urale $v$ epohu feodalizma, Sverdlovsk, Ural'skoe Otdelenie AN SSSR, 1991, pp. 151-152. 
bénéficiaient de facto d'un statut «semi-militaire» plus élevé65. Cependant, l'affaire ne s'était pas réduite à une simple corrélation. Les fonctionnaires des mines étaient, en réalité, groupés en trois catégories on ne peut plus militaires : généraux, officiers supérieurs et officiers subalternes. En 1734, ceux des ingénieurs et techniciens des mines qui travaillaient aux usines métallurgiques étaient assimilés à des officiers en campagne. En 1761, les officiers des mines exerçant aux usines Kolyvano-Voskresenskie ont reçu le même statut que les officiers de l'artillerie ou du génie (donc supérieur à celui des officiers de l'armée) ${ }^{66}$. À partir de 1755 , ils ont eu leur propre uniforme ${ }^{67}$. Pour devenir un vrai corps il ne manquait plus qu'un élément - un établissement scolaire qui fournirait régulièrement des spécialistes de la qualification demandée. Cette institution - l'École des Mines bien connue - a effectivement été créée en 1773 à Saint-Pétersbourg68.

Notons que cette voie n'était pas inaccessible à d'autres groupes professionnels, par exemple aux constructeurs de vaisseaux qui ne l'ont pas utilisée. Parmi les raisons de cette situation, l'une semble essentielle : à la différence des fonctionnaires des mines, les constructeurs de vaisseaux n'appartenaient pas à une administration autonome mais dépendaient de celle de la marine. Les processus d'auto-organisation qui, au sein du Berg-Collège, opéraient sans frein se voyaient subordonnés, dans le cas des constructeurs de vaisseaux, aux intérêts de l'instance de tutelle. Or ces intérêts étaient loin de coïncider sur tous les points, surtout sous les successeurs de Pierre Ier beaucoup moins soucieux que lui du développement de la flotte.

\section{La formation « de facto »}

La deuxième direction s'appuie sur deux piliers : la hiérarchie des fonctionnaires selon la Table des rangs et l'existence, au sein de chaque administration, d'un certain nombre de collaborateurs recrutés conformément à l'état prévisionnel des effectifs. C'est cette subtilité qui la distingue de la formation du corps « de jure » où l'état des effectifs même représente un certain ensemble hiérarchisé de grades

65. Ainsi, les ober-berg-gauptman des $3^{\mathrm{e}}$ et $4^{\mathrm{e}}$ classes correspondaient aux grades de générallieutenant et de général-major; les šihtmejster de $13^{\mathrm{e}}$ et $14^{\mathrm{e}}$ classes - aux grades de sous-lieutenant et d'enseigne, etc.

66. PSZ, XLI, n 6559, du 23.03.1734, p. 198; n 11185 du 12.01 .1761 , p. $339 ; \mathrm{n}^{\circ} 11241 \mathrm{du}$ 27.04.1761, p. 340; XLII, I, pp. 326, 327. L. E. Šepelev, Tituly, mundiry, ordena v Rossijskoj imperii, op. cit. (supra note 55), p. 92;

67. L. E. Šepelev, Ibid., p. 143.

68. Cf. T. S. Dubrava, Leningradskij gornyj institut, Leningrad, [LGI], 1957, 85 p.; « Gornye učebnye zavedenija », in S. N. Južakov, ed. Bol'šaja enciklopedija, Saint-Pétersbourg, s.d., 7, pp. 298-299; "Gornye učilišča », in Enciklopedičeskij slovar', Saint-Pétersbourg, F.A. Brokgauz, I.A. Efron, 1893, 9, pp. 300-302; Kell' « Leningradskij gornyj institut », in BSE, 3e ed., Moscou, SE, 1973, 14, p. 319; N. I. Eremin, «Leningradskij gornyj institut », in Gornaja enciklopedija, Moscou, 1987, 3, pp.181-182; I. I. Šafranovskaja, ed., Leningradskij gornyj institut i Akademija nauk SSSR, Leningrad, 1978, 123 p.; N. V. Levenberg, ed., Leningradskij ordena Lenina i ordena Trudovogo Krasnogo Znameni gornyj institut imeni G. V. Plehanova (1773-1973), Moscou, Vysšaja škola, 1973, 320 p. 
personnels. Cependant, dans notre cas, cette fonction est assurée par la Table, document réglementaire extérieur à toute administration concrète, et unique pour l'ensemble du pays.

$\mathrm{Au}$ XVIII ${ }^{\mathrm{e}}$ siècle, cette situation se rencontre dans certains milieux professionnels, par exemple dans celui des géodésiens et des arpenteurs, ou encore dans la marine ${ }^{69}$. N'oublions pas les topographes militaires (quartiers-maîtres) qui, en quête d'une forme d'organisation appropriée, se sont finalement engagés, euxaussi, dans cette voie. La création, en 1763, de 1'État-Major général revêt dans ce contexte une signification toute particulière vu le rôle que cette instance a été appelée à jouer dans l'évolution de ladite administration ${ }^{70}$.

L'introduction d'un uniforme particulier pour une administration ou un détachement donné constitue également un pas vers la formation du corps de facto. Citons, à titre d'exemple, le cas du Département de la communication par eau qui s'applique à munir ses personnels d'un uniforme spécial dont le port est obligatoire à partir de 1798. À la différence de l'uniforme militaire, celui des administrations civiles correspondait au rang de la fonction et non pas au rang du čin ${ }^{71}$. Mais au fond, est-il vraiment si important? Et, dans l'affirmative, quel est son rôle? Dans les conditions russes, l'uniforme avait, nous semble-t-il, une double fonction sémiotique : élever le statut de son porteur aux yeux de la société et contribuer à la consolidation corporative des porteurs du même uniforme ${ }^{72}$. La consolidation corporative est, d'ailleurs, un des indices mentaux les plus importants du fonctionnement d'un corps.

69. Il s'agissait, bien entendu, de certains métiers techniques particuliers et non pas de l'ensemble de cette administration.

70. A. V. Postnikov, op. cit. (supra note 45) ; « General-kvartirmejster », in S. N. Južakov, ed., Bol'šaja enciklopedija, Saint-Pétersbourg, 1901, 6, p. 388; « General'nyj štab », M. V. Zaharov, in BSE, 3e éd., Moscou, SE, 1971, 6, pp. 223-224; « Glavnyj štab », Ibid., pp. 772-773; L. A. Gol'denberg, A. V. Postnikov, «Dokumental'nye pamjatniki russkoj kartografii XVIII v. », in Pamjatniki nauki i tehniki 1985, Moscou, Nauka, 1986, pp. 154-171; N. P. Glinoedskij, Istorija russkogo General'nogo štaba, 1-2, Saint-Pétersbourg, 1883-1894; V. S. Kusov, Kartu sozdajut pervoprohodcy, Moscou, Nedra, 1983, 70 p.; O. A. Sergeev, N. A. Urmaev, « K istorii razvitija voenno-topografičeskoj služby », Vestnik Voenno-inženernoj akademii RKKA..., op. cit. (supra note 45), pp. 132-146.

71. L. E. Šepelev, Tituly, mundiry, ordena $v$ Rossijskoj imperii, op. cit. (supra note 55), pp. 143-145.

72. Il est intéressant de citer, à cette occasion, quelques lignes extraites du projet de l'École hydraulique (1803/1804), signé par les généraux F. Dewollant et V. Tolstov : « [...] on ne peut ignorer à quel point offrir un uniforme aux jeunes gens exerçant au sein de la communication sera utile pour les stimuler [...] comme cela existe déjà au berg-collège et aux départements des postes et des forêts car les apparences séduisent les yeux jeunes [...]». Rossijskij gosudarstvennyj istoričeskij arhiv (RGIA), f. 159, op. 1, d. 16 (Ob učreždenii gidravličeskogo učilišča, 1802-1805), ff. 14-14v. Notons qu'il s'agit ici d'un uniforme civil qu'on commence juste à introduire dans l'Empire. Sur les uniformes civils, voir L. E. Šepelev, « Graždanskie mundiry v dorevoljucionnoj Rosii v svjazi s ih značeniem dlja istoričeskih issledovanij », Vspomogatel'nye istoričeskie discipliny, 22, 1991, pp. 25-52. 


\section{La militarisation directe}

Cette troisième voie consistait à tenter la création directe de corps militarisés pour encadrer les spécialistes civils. Par exemple, en 1737-1740, on a essayé de mettre ainsi sur pied un corps militarisé des architectes. Cette tentative remonte au fameux document «Dolžnost'arhitekturnoj ekspedicii » (Fonction de l'expédition de l'architecture) sorti des tréfonds de la Commission pour le bâtiment de Saint-Pétersbourg et détaillant la structure de l'administration de l'architecture ${ }^{73}$. Les auteurs eux-mêmes étaient convaincus d'avoir modelé leur « expédition » sur l'exemple du corps analogue en France. Cette dernière idée remonte, de toute évidence, au rapport de Le Blond « Sur la direction des travaux de construction », traduit en russe vers la fin de $1716^{74}$. La tentative a échoué pour des raisons plutôt politiques : l'architecte P. Eropkin, âme de ladite Commission et promoteur principal du projet, se trouva mêlé au complot d'A. Volynskij et, le 27 juin 1740, il fut décapité.

\section{Le dualisme militaro-civil}

Les promoteurs de cette dernière direction semblaient tout d'abord envisager la création d'un corps d'ingénieurs civils. C'est dans cette lignée que s'inscrit, par exemple, la fameuse tentative entreprise par F. W. Baur en vue de lancer le Corps des hydrauliciens en octobre $1782^{75}$.

Ce corps était censé avoir une grille de grades civils interne qui prévoyait 16 (8 et 8 ) hydrauliciens du $1^{\mathrm{er}}$ et du $2^{\mathrm{e}}$ degré. Cependant, à en juger d'après l'entourage de Baur et d'après le texte de l'ukase, ses effectifs devaient être formés essentiellement d'ingénieurs militaires, d'officiers de l'État-Major général (topographes militaires) et de spécialistes étrangers. Les officiers de ces corps affectés en surplus pour assister les hydrauliciens pouvaient espérer, avec le temps, être incorporés à leur tour. Compte tenu de ce qui se pratiquait à l'époque, on peut supposer qu'une partie au moins de ces nouvelles recrues d'hydrauliciens auraient gardé leurs grades militaires et auraient continué à être inscrits de facto sur les listes de leurs anciens corps même si leurs appointements dans leurs corps d'origine avaient été

73. Composition de la Commission : président effectif : B. Ch. Münich; membres : M. Golovin, A. Naryškin, le général-major Izmajlov, l'ober-ster-krigs-kommissar Sajmonov, le conseiller de l'artillerie I. Unkovskij, le major de fortification Ruh et l'architecte P. M. Eropkin. La Commission fut créée le 10 juillet 1737. S. S. Bronštejn, « Peterburgskaja arhitektura 20-30-h godov XVIII veka », in I. E. Grabarja, ed. Russkaja arhitektura pervoj poloviny XVIII v. Issledovanija i materialy, Moscou, Gosizdat lit-ry po isk-vu i arh-re, 1954, pp. 181-238; " "Dolžnost' Arhitekturnoj ekspedicii” : Traktat-kodeks 1737-1740 godov », Arhitekturnyj arhiv, Moscou, 1, 1946, pp. 5-100; N. A. Evsina, Arhitekturnaja teorija v Rossii XVIII v., Moscou, Nauka, 1975, pp. 7796; PSZ, X, n 7323 du 10.07.1737, pp. 216-217; T. F. Savarenskaja, D. O. Tvidkovskij, F. A. Petrov, Istorija gradostroitel'nogo iskusstva, Moscou, Strojizdat, 1989, pp. 111-118; V. Sokolov, «Sud'ba Petra Eropkina », Leningradskaja panorama, 9, 1989, pp. 36-40.

74. « “Dolžnost' Arhitekturnoj ekspedicii”... », art. cit. (supra note 73).

75. PSZ, XXI, $\mathrm{n}^{\circ} 15562$ du 27.10.1782, p. 718; n $^{\circ} 15563$ du 31.10.1782, p. 719. 
complètement ou partiellement suspendus (une forme de mission de détachement). D'autant plus qu'initialement, faute d'écoles spécialisées en hydraulique, les effectifs de ce corps devaient être formés dans le Corps des cadets de l'artillerie et du génie ${ }^{76}$.

Cet état ambivalent que nous avons appelé le dualisme militaro-civil aurait donc été maintenu dans le cas cité grâce à l'appartenance formelle d'une partie des ingénieurs à deux corps simultanément. Le dernier pas qu'il restait à franchir consistait à formaliser ce dualisme au sein d'un seul et même corps. Ce qui sera mis en application au siècle suivant.

\section{Mise en place des corps techniques militaires et militarisés 1810-1860}

Les réformes d'Alexandre Ir au début du XIX ${ }^{\mathrm{e}}$ siècle ouvrent un nouveau volet dans l'histoire du développement des corps techniques russes. Les structures d'administration et de gestion sont les premières à être touchées et à être complètement réorganisées. Les changements visent le cœur même de l'ancien système puisque celui des collèges est supprimé et remplacé par un réseau de ministères, organismes de gestion beaucoup plus souples et performants.

Dans le domaine du génie, les fruits de cet élan modernisateur ne se font pas attendre. Ainsi, lorsque se crée, en 1802, le ministère de l'Armée de terre (Minis-

76. Dans la riche littérature russe et soviétique l'existence du Corps des hydrauliciens n'a pas été mise en cause pendant plus de 150 ans. A. Savel'ev, Istoričeskij očerk inženernogo upravlenija v Rossii, op. cit. (supra note 35) ; V. E. Prudnikov, Russkie pedagogi-matematiki XVIII V., op. cit. (supra note 47) ; Kratkij istoričeskij očerk razvitija i dejatel'nosti Vedomstva Putej soobščenija za sto let ego suščestvovanija (1798-1898), Saint-Pétersbourg, 1898, 218-13 p.; Istoričeskij očerk razvitija organizacii Vedomstva putej soobščenija, [Saint-Pétersbourg, 1908], 119 p.; A. N. Bogoljubov, I. Z. Šokalo, eds, Istorija mehaniki v Rossii, Kiev, 1987, 392 p.; Viktor Romanovič, Kratkij istoričeskij očerk sformirovanija Korpusa Putej Soobščenija, [s.1.], 7.02.1848, 95 p. (Manuscrit, bibliothèque de l'Institut des voies de communication de Saint-Pétersbourg, $\mathrm{n}^{\circ}$ 5329) ; Leningradskij ordena Lenina Institut inženerov železnodorožnogo transporta imeni akademika V. N. Obrazcova 1809-1959, Moscou, VIPO MPS, 1960, 388 p.; «Transportnoe obrazovanie », in BSE, 3e ed., Moscou, SE, 1977, 26, pp. 159-161; P. V. Šcusev, Mosty $i$ ih arhitektura, Moscou, Gosizdat lit-ry po str-vu i arh-re, 1952, p 207; M. I. Voronin, Issledovanie stanovlenija i razvitija transportnoj nauki i tehniki v oblasti izyskanij i proektirovanija železnyh dorog ot ih vozniknovenija do načala socialističeskoj industrializacii v SSSR : Diss. ... dokt. tehn. nauk, Leningrad, LIIŽT, 1973, 1, p. 17; M. M. Voronina, Gabriel' Lamé 1795-1870, Leningrad, Nauka, 1987, p. 29; A. N. Bogoljubov, Avgustin Avgustinovič Betankur [Bétancourt] 1758-1824, Moscou, Nauka, 1969, 152 p.; Rossijskij gosudarstvennyj voenno-istoričeskij arhiv (RGVIA), f. 826, op. 3, predislovie, ff. 1-5; [Čarukovskij], « Očerk razvitija Instituta Inženerov Putej Soobščenija Imperatora Aleksandra I », in Spisok lic okončivših kurs nauk v Institute Inženerov Putej Soobščenija Imperatora Aleksandra Is 1811 po 1882 g., Saint-Pétersbourg, 1883, 47 p. Ayant exploré ce sujet à fond, nous avons été amenés à conclure qu'en fait il était toujours question d'un corps-fantôme qui n'avait existé que sur le papier. L'ukase relatif à sa création a été signé le 11 février 1783. Cependant, son initiateur, F. Baur, étant mort peu après, sa création effective n'a jamais eu lieu. D. Ju. Guzevič, Razvitie mostostroenija v Rossii..., op. cit. (supra note 16), t. 1, pp. 67-68, t. 2, pp. 166-167; D. Ju. Guzevič, I. D. Guzevič, «"Tajna” Korpusa gidravlikov », Voprosy istorii estestvoznanija i tehniki, 2, 1994, pp. 56-59; Id., « Posleslovie k sobstvennoj stat'e », Ibid., 4, 1995, pp. 162-163. 
terstvo voenno-suhoputnyh sil) une Expédition du génie voit également le jour, indépendante, cette fois-ci, de celle de l'artillerie ${ }^{77}$.

La réorganisation toucha également nombre d'autres administrations, et notamment les services de topographie militaire directement impliqués dans les prospections hydrotechniques et routières ${ }^{78}$.

Même si elles ne concernaient alors que les administrations, toutes ces réformes ont préparé le terrain pour que soient réorganisés et modernisés les corps techniques hérités du XVIII ${ }^{\mathrm{e}}$ siècle. Ce terrain s'est avéré également propice à l'émergence accélérée d'organismes nouveaux.

L'effort modernisateur s'est manifesté avec le plus d'éclat dans la réforme complexe des services de transports. Par une cascade d'ukases deux administrations rachitiques et dépendantes - le Département des communications par eau et l'Expédition pour l'aménagement des routes dans l'État - sont réorganisées en juillet 1810 et fusionnent en une seule et unique Direction générale des voies de communication (Glavnoe upravlenie putej soobščenija, GUPS). Simultanément, en mars 1810, est enfin créé l'organisme professionnel destiné à encadrer les spécialistes en matière de transports et de travaux publics - le Corps des ingénieurs des voies de communication (Korpus inženerov putej soobščenija, CIVC).

La naissance de ce corps organisé selon de nouvelles bases marque un tournant décisif dans l'histoire des corps d'ingénieur russes car la forme et la structure qu'il revêt déterminent les voies de leur développement pour les années à venir. En même temps, le processus d'émergence de cet organisme devenu classique n'a jamais été retracé ni dans son ensemble ni dans ses détails, et pourtant seule une étude minutieuse de son développement permettrait de rendre compte des batailles invisibles auxquelles il a donné lieu, avec leurs gagnants et leurs perdants, leurs gloires et leurs misères, leurs ambitions ruinées et leurs devoirs accomplis.

\section{Réforme de l'administration des voies de communication : un exemple complexe}

Essayons donc d'analyser plus en détail le mécanisme de cette réorganisation. Notons, pour commencer, qu'elle coïncide avec la deuxième vague de réformes d'Alexandre I ${ }^{\mathrm{er}}$. La première, en 1802 et 1803, balaie le système des collèges au profit d'un système de ministères. Elle donne également lieu à la naissances des universités, etc. Menées avec une hâte excessive par le jeune tsar et ses jeunes

77. L'indépendance de cette administration est définitivement fixée par la loi en 1804. RGVIA, f. 826, op. 3 , predislovie, ff. 1-5.

78. En 1796 (-1797?) l’État-Major général fut réorganisé en « Suite de Sa Majesté Impériale des Quartiers-Maîtres » (Svita Ego Imperatorskogo Veličestva po kvartirmejsterskoj časti). Lors de la création de 1'État-Major principal (Glavnyj štab) en 1815, cette Suite y fut intégrée sous le nom de Direction du général-quartier-maître. Le Dépôt des cartes (Bureau de topographie militaire), créé en 1796, devint avec le temps un vrai centre de cartographie et de géodésie à l'échelle du pays. Plus tard il fut connu sous le nom du Département de topographie militaire de l'État-Major principal. Cf. les documents cités supra dans la note 70. 
conseillers, encore peu experts dans les affaires d'administration, ces réformes s'avèrent bientôt insuffisantes, si bien qu'en 1810-1811 une série d'autres réorganisations sont entreprises sous la direction, cette fois, du secrétaire d'État M. M. Speranskij, homme politique d'envergure connu pour ses opinions libérales. Cependant, la situation politique a changé, les dispositions du tsar ne sont plus les mêmes, et le programme de réformes grandioses visant à recréer l'ensemble de l'appareil du gouvernement qu'il a lui même initié perd de l'élan, commence à piétiner, puis s'étouffe. Speranskij a juste le temps de faire les premiers pas mettre en place le Conseil d'État et réorganiser un certain nombre d'administrations (dont celle qui nous intéresse) - qu'Alexandre l'envoie en exil mettant fin au rêve libéral de sa jeunesse. Ces événements se déroulent en $1812^{79}$.

Si la réforme des administrations de transports a cependant réussi c'est que, en plus d'une conjoncture favorable, elle a été soutenue par des dignitaires et des hauts fonctionnaires par ailleurs très influents. Ainsi, la nécessité des changements a été très tôt perçue par le directeur général des communications par eau, le comte Rumjancev, et par les membres de son administration (Departament vodjanoj kommunikacii, DVK), notamment, par l'ingénieur-lieutenant-général F. Dewollant. L'ascension rapide de Rumjancev qui, en 1802, prend la tête du ministère du Commerce, puis, en 1807, accède au poste du chancelier d'État, profite beaucoup à la rénovation des administrations de transports qu'il continue à diriger. Car, outre le rôle de directeur général du Département des communications par eau, intégré au ministère du Commerce, le comte assure d'office la gestion du second organisme autonome existant dans le domaine - l'Expédition pour l'aménagement des routes dans l'État.

C'est à ce triple titre de ministre, de chancelier et de directeur des administrations de transports que Rumjancev prône les changements. Pour commencer, il procède à l'étude de ce qui se fait à l'étranger : deux missions hydrauliques se mettent aussitôt en route, l'une vers la Grande-Bretagne (1803/1805), l'autre vers la France (1807/1808) ; des commissionnaires sont également délégués en Bavière.

De son côté, Dewollant - avec les généraux De Witte et Gerhard - rédige en 1803/1804 le projet de l'École centrale hydraulique destinée à former les ingénieurs des transports. En même temps il propose d'élargir le Département des communications par eau en créant auprès de son Bureau de dessins un corps nouveau, celui des hydrauliciens. Selon son idée, ce corps devait inclure les ingénieurs hydrauliciens des $1^{\mathrm{re}}, 2^{\mathrm{e}}$ et $3^{\mathrm{e}}$ classes, des apprentis, des maîtres, un mécanicien et un architecte ${ }^{80}$. Certains indices font penser que le projet a été élaboré à l'instigation d'Alexandre ${ }^{\mathrm{er}}$. Cependant à l'époque - et pour des raisons confuses - il n'a pas été mis en application ${ }^{81}$.

79. Cf. S. V. Mironenko, Samoderžavie i reformy. Političeskaja bor'ba v Rossii v načale XIX veka, Moscou, Nauka, 1989, 240 p.

80. RGIA, f. 159, op. 1, d. 16 (Ob učreždenii gidravličeskogo učilišča, 1802-1805), 40 f.

81. Pour plus de détails sur cette période préparatoire, voir nos travaux déjà cités ainsi que D. Guzevič, « Pervyj inženernyj VUZ Rossii », Tehnika i nauka, 9, 1986, p. 41; D. Guzevič, I. Guzevič, «Franc Pavlovič Devolant (1752-1818) », in Tvorcy otečestvennoj tehniki, Moscou, Nauka, 2001, 10 p. (à paraître). 
À la fin de 1808, grâce aux manœuvres diplomatiques de Rumjancev, Dewollant reçoit un renfort en la personne d'Augustin Bétancourt, ingénieur espagnol invité au service de la Couronne lors de la rencontre des deux empereurs, Napoléon et Alexandre, à Erfurt en octobre $1808^{82}$. Recruté avec le grade de général-major dans la Suite de Sa Majesté Impériale, Bétancourt est aussitôt mobilisé pour s'occuper, avec les autres généraux supérieurs du DVK, des problèmes de cette administration à la dérive. En l'absence de Rumjancev, en mission à l'étranger, le Département doit effectivement faire face à un problème grave et d'une urgence stratégique car le système hydraulique Vyšnevolockaja (artère principale qui relie la capitale impériale au reste du pays) se révèle être dans un état catastrophique.

Compte tenu de la gravité de la situation, l'empereur procède à la création d'un Comité ad hoc chargé de trouver une solution rapide et efficace aux problèmes du DVK. Ce Comité, placé sous la présidence du ministre des Affaires intérieures, ouvre ses séances au début de l'année 1809. Il comprend quatre membres : trois généraux (Bétancourt, Dewollant et Gerhard), et un gentilhomme de la chambre (kamer-junker), Aleksandr Sablukov, futur général de deux corps techniques celui des voies de communication et celui des mines - , et inventeur renommé.

82. Augustin Bétancourt (1758-1824) fut effectivement la figure de proue de la première histoire de l'administration des voies de communication russe. Âme et moteur principal de sa réforme, un de ses premiers directeurs généraux, il fut également promoteur de l'enseignement rénové dispensé à l'Institut du corps, première grande école d'ingénieurs en Russie. Cf. A. N. Bogoljubov, Avgustin Avgustinovič Betankur..., op. cit. (supra note 76) ; « Očerk razvitija Instituta Inženerov Putej Soobščenija... », art. cit. (supra note 76) ; L. F. Nikolaj, Kratkie istoričeskie dannye o razvitii mostovogo dela $v$ Rossii, Saint-Pétersbourg, 1898, 120 p.; S. P. Acosta, El ingeniero Agustin de Béthencourt y Molina, La Laguna de Tenerife, 1958, 50 p.; A. Cioranescu, Agustin de Betancourt su obra technica y cientifica, La Laguna de Tenerife, 1965, 199 p.; A. R. De Armas, El Real Gabinete de máquinas del buen retiro [...], Madrid, Fundacion Juanelo Turriano, 1990, pp. 51-60; Id., Ciencia y tecnologia en la España ilustrada : La Escuela de Caminos y Canales, Madrid, ed. Turner, 1980, 557 p.; etc. La liste d'ouvrages portant sur ce sujet compte plus de 200 titres en russe, espagnol, français, anglais, allemand. Voir aussi [V. A. Kiprianov], Očerki (Iz zapisok V. A. K.), Moscou, 1882, 1, pp. 163-175.

Les origines de son élan réformateur sont à rechercher dans le parcours professionnel peu commun de cet homme doué de talents divers, particulièrement sensible aux vents nouveaux qui soufflaient alors dans l'Europe occidentale. La formation initiale qu'il avait reçue à Madrid dans l'établissement royal de Saint-Isidore et à l'Académie des Beaux-Arts de cette ville fut poursuivie et affinée à Paris où il séjourna pendant six ans (1785-1791) comme chef de l'équipe des stagiaires espagnols accueillie par Perronet à l'École des ponts et chaussées. Cette expérience fut plus tard enrichie par des séjours consécutifs en Espagne, en Grande-Bretagne et de nouveau en France où, en collaboration avec J. M. Lanz, il prépara et publia aux frais de l'École polytechnique son fameux manuel Essai sur la composition des machines, travail pionnier qui lança les bases de la nouvelle science des machines. J. M. Lanz, A. Bétancourt, Essai sur la composition des machines, Paris, 1808, 120 p.; Id., $2^{\mathrm{e}}$ ed., Paris, 1819, 184 p.; A. N. Bogoljubov, Istorija mehaniki mašin, Kiev, Naukova dumka, 1964, pp. 58-70. Il fut pour l'Espagne, sa patrie, un réformateur infatigable qui lança et réussit la création de trois organismes favorisant le développement de l'art et des sciences de l'ingénieur : le Cabinet des machines (el Gabinete de Maquinas, 1791) ; le Corps des ingénieurs des routes et des canaux espagnol (el Cuerpo de ingenieros de caminos y canales, 1799) et l'École des routes et des canaux (l'Escuela de caminos y canales de Madrid, 1802). Ces expériences multiples et variées furent mises par Bétancourt au profit de son nouveau service en Russie. 
Selon le témoignage de Dewollant, tous les travaux du Comité ont été dirigés par Bétancourt ${ }^{83}$. C'est à l'Espagnol également que revient l'initiative des changements qui ont causé la démission de son protecteur, Rumjancev, du poste du directeur général.

Après trois mois de travail intense, le Comité formula un certain nombre de propositions soumises aussitôt à l'empereur et approuvées par ce dernier. Le Comité insistait surtout sur la nécessité de confier la Direction générale des communications à une personne dont ce serait la charge unique et qui bénéficierait, de surcroît, des pleins pouvoirs dans trois gouvernements - Tver', Novgorod et Jaroslavl' - traversés par les artères de transports principales. Quand, en mars 1809, Rumjancev rentre à Saint-Pétersbourg, les propositions du Comité prônant, de fait, sa démission, sont déjà confirmées ${ }^{84}$.

L'ukase impérial du 18 avril 1809 légitime donc le nouvel ordre des choses : la direction générale du Département des communications par eau est confiée, selon les recommandations du Comité, à une seule et même personne, nommée simultanément gouverneur général (general-gubernator) des trois gouvernements stratégiques mentionnés. Suit le nom de l'élu : Petr Friedrich Georg de Holstein-Oldenbourg, prince de sang et beau-frère du monarque, âgé alors de $25 \mathrm{ans}^{85}$.

Malgré sa jeunesse, le prince ne manquait ni d'énergie ni de bon sens ni, surtout, de bonne volonté. Une fois entré en fonction, il charge Dewollant de lui préparer dans la quinzaine une série de documents nécessaires à la poursuite de la réforme du DVK. Le 28 avril, Dewollant lui soumet les rapports demandés où sont détaillées les activités du Département, analysées les causes de la mauvaise exécution des travaux, fournie la description géographique et statistique des voies de communication dans l'Empire.

Simultanément, Bétancourt soumet à l'empereur le projet de l'organisation du corps des ingénieurs-hydrauliciens et constructeurs des ponts et chaussées et d'une

83. F. De Wollant, Précis de mes services en Russie 1787-1811, Saint-Pétersbourg, 1811, f. 63v. (Manuscrit, copie, bibliothèque de l'Institut des voies de communication de Saint-Pétersbourg, A.VII.32). Voir aussi : General' Fransua De-Volant, Očerk moej služby v Rossii (1787-1811 gg.), Odessa, Odesskij morskoj torgovyj port, 1999, 136 p., ou l'édition en anglais : General Francois De-Volant, The essay of my service in Russia (1787-1811), Odessa, Odessa Marine Trade Port, 1999, 136 p. - communiqué par N. G. Košanskij.

84. D'ailleurs, comme Dewollant le rapporte dans ses mémoires, Rumjancev n'avait rien contre l'idée de quitter ce poste car sa carrière politique était alors en pleine ascension. Cf. Ibid. En 1810, il accédera effectivement au poste de président du Conseil d'État mais deux ans plus tard, à la suite d'un différend avec Alexandre I ${ }^{\mathrm{er}}$, il sera obligé de quitter ce poste et s'éloignera progressivement des affaires.

85. L'ascension du jeune prince Holstein-Oldenbourg fut vertigineuse et courte. Venu en Russie en 1808, il reçut aussitôt le grade de lieutenant-général, fut nommé gouverneur général de la province de 1'Estland; en avril 1809, il épousa la grande-duchesse Ekaterina Pavlovna, sœur bien-aimée d'Alexandre I ${ }^{\mathrm{er}}$, recevant ainsi le titre d'Altesse Impériale. De santé fragile, il fut malheureusement emporté par la maladie en 1812. Cf. A. N. Bogoljubov, Avgustin Avgustinovič Betankur... op. cit., p. 14; PSZ, XLI, 1 (Ukazatel' hronologičeskij), Saint-Pétersbourg, 1830, pp. 713, 718; Gazette nationale ou Le Moniteur Universel, 17.12.1808, n 352, p. 1585; $11.02 .1809, \mathrm{n}^{\circ} 42$, p. $161 ; 12.02, \mathrm{n}^{\circ} 43$, p. $165 ; 14.02, \mathrm{n}^{\circ} 45$, p. $173 ; 17.02, \mathrm{n}^{\circ} 48$, p. 185 ; $29.05, \mathrm{n}^{\circ} 149$, p. $591 ; 30.05, \mathrm{n}^{\circ} 150$, p. 593 . 
école spécialisée pour les former. Selon Dewollant, certains passages de ce projet étaient presque littéralement calqués sur les règlements introduits en France en 1806 par Napoléon.

Afin d'étudier tous ces documents, une commission spéciale est créée à la mimai à Pavlovsk sous la présidence du nouveau directeur général. Outre Bétancourt et Dewollant, elle compte deux autres membres, Sénovert ${ }^{86}$ et Lubjanovskij ${ }^{87}$, qui ont encore un rôle à jouer dans l'histoire de la nouvelle administration. La commission siège à huis clos et ses travaux se poursuivent jusqu'au début juillet dans le secret le plus absolu.

L'essence de son activité transparaîtra par la suite à travers les documents issus de son sein et les actes qui s'en suivront. Certains aspects de ce travail restés en marge des documents fondateurs nous sont par ailleurs relatés par un témoin précieux, Franz Dewollant en personne.

Les débats portaient évidemment sur le projet de la nouvelle administration, sur les formes à donner au futur corps des ingénieurs des voies de communication et sur la meilleur façon de les instruire. L'esquisse de la future institution s'y dessinait, nourrie par la double expérience de ses initiateurs. Le projet de Bétancourt, quoique plus performant, avait effectivement beaucoup de points communs avec celui de l'École centrale hydraulique proposé par le Hollandais cinq ans auparavant. Tout le monde était conscient de la difficulté qu'il y aurait à trouver en Russie des professeurs qualifiés pour enseigner à l'institut. On reconnut utile et raisonnable d'inviter à ces fins, avec l'accord du gouvernement français, quatre à cinq ingénieurs formés à l'École polytechnique de Paris.

On sait que le Corps des ingénieurs des voies de communication était organisé sur un mode militaire. Les origines et la paternité de cette idée font pourtant toujours l'objet de discussions savantes. Selon les souvenirs de Dewollant, l'ordre de trouver le moyen d'en faire un corps militaire émanait de l'empereur, soucieux de le rendre plus attrayant aux yeux des futurs officiers ${ }^{88}$. Certains historiens en attribuent l'idée à Bétancourt ${ }^{89}$. D'autres encore estiment que cette idée n'avait rien

86. Étienne-François de Sénovert, ingénieur militaire, émigré de l'Ancien Régime, sera pendant des années ami et proche collaborateur de Bétancourt en Russie.

87. F. P. Lubjanovskij, alors secrétaire d'État et ancien subordonné de Speranskij, deviendra par la suite chef du Cabinet du prince. C'est par son biais que seront plus tard transmis à Speranskij, pour qu'il les soumette à l'approbation de l'empereur, tous les rapports et les propositions formulés au sein de l'administration des voies de communication. Kratkij istoričeskij očerk razvitija i dejatel'nosti Vedomstva Putej soobščenija..., op. cit. (supra note 76), p. 29.

88. F. De Wollant, Précis de mes services en Russie..., op. cit. (supra note 83), f. 68v.

89. Bétancourt était, effectivement, parfaitement au courant du système des grades civils en vigueur dans le Corps des ingénieurs des ponts et chaussées français. Arrivé en Russie il a toutefois très vite senti tous les avantages que pouvaient offrir dans ce pays « le grade et l'uniforme militaire... » (F. Vigel, cité d'après A. N. Bogoljubov, Avgustin Avgustinovič Betankur..., op. cit. (supra note 76), p. 23; voir aussi chez A. Del'vig : « Le service militaire a toujours été très distingué en Russie », A. I. Del'vig, Vospominanija. Polveka russkoj žizni, Moscou, Leningrad, Academia, 1930, I, p. 91). Ayant compris cela, Bétancourt aurait obtenu les grades militaires pour les élèves de l'Institut et donc pour l'ensemble du CIVC. 
d'original puisque le DVK était déjà, de fait, organisé sur le mode militaire car la plupart de ses membres s'y trouvaient simplement détachés tout en restant ingénieurs du Corps du génie militaire et pouvaient donc être à tout moment révoqués pour regagner l'armée ${ }^{90}$. Notons que Sénovert, à titre d'ex-ingénieur du roi avec dix-sept ans d'ancienneté au service français, aurait pu, lui aussi, influencer le débat sur le statut du corps ${ }^{91}$. Quoiqu'il en fût, l'idée était dans l'air, et Bétancourt l'a bien perçue en donnant au nouveau corps sa forme dualiste parfaitement achevée ${ }^{92}$.

90. « Istoričeskij očerk učastija vedomstva putej soobščenija v Otečestvennoj vojne », Žurnal Minsterstva putej soobščenija, 7, 1912, pp. 3-43.

91. Le fait (confirmé par le témoignage de Dewollant) que Sénovert a participé à l'élaboration du projet de réforme semble effectivement nuancer le point de vue traditionnel qui fait de Bétancourt le principal, sinon l'unique responsable de la militarisation du CIVC. Élève de l'École du génie et de l'artillerie de Mézières (promotion 1774), il fut à sa sortie intégré au

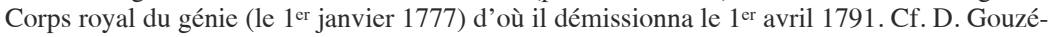
vitch, I. Gouzévitch, «Etienne-François de Senovert, traducteur en français des oeuvres de J. Steuart : Trois volets d'une vie (1753-1831) », in James Steuart en 1995 : Colloque International (14-16 septembre 1995, Châteu de Vizille) : Résumés des communications, [Grenoble, 1995], 1-22 p.; A. Blanchard, Dictionnaire des ingénieurs militaires 1691-1791, Montpellier, 1981, pp. 688-689; Id., Les ingénieurs du «Roy » de Louis XIV à Louis XVI. Étude du Corps des fortifications, Montpellier, 1979, pp. 290-292. Or ce fut l'époque où deux grilles de grades y étaient utilisées en parallèle. Voilà ce qu'écrit à ce sujet Anne Blanchard, historienne reconnue des ingénieurs du Roi : «Lors de l'ordonnance royale de 1776 qui réorganise le corps des ingénieurs en corps royal de Génie, le texte officiel avalise ce sens au moment où, paradoxalement, les ingénieurs du roi vont désormais s'appeler officiers du Génie ». Ibid., pp. 290-291. Cette ordonnance stipulait la mise en corrélation des grades anciens du corps (qui étaient le plus souvent aussi des fonctions, par exemple directeur des fortifications, ingénieur en chef, ingénieur ordinaire, etc.) avec les grades d'officiers militaires (lieutenant-colonel, chef de brigade, etc.). Cette réforme qui offrait, de fait, au corps technique militaire une structure militaire conforme visait à régulariser le système de grades, titres et fonctions et non pas à donner à un corps civil militarisé une double structure interne. Cependant, Sénovert fut témoin de l'état où le corps avait de facto deux grilles de grades.

92. Citons à cette occasion l'extrait du « Décret concernant l'administration des communications par eau et par terre » (Učreždenie ob upravlenii vodjanyh i suhoputnyh soobščenij), PSZ, $\mathrm{XXX}, \mathrm{n}^{\circ} 23996$ du 20.11.1809,pp. 1305-1339) qui décrit cette structure dont les modifications ultérieures portent essentiellement sur le nombre de postes vacants :

« $§$. Est statué le Corps des ingénieurs, qui doit être organisé comme un corps militaire (komu byt' na položenii voinskom).

$\S$ 6. Ce Corps sera composé de : 3 généraux-inspecteurs [conseillers du directeur général et membres du Conseil des voies de communications - D.I.G.], 10 chefs d'arrondissement, 15 directeurs de travaux, 20 directeurs-conducteurs de travaux, 30 ingénieurs de $1^{\text {re }}$ classe, 45 ingénieurs de $2^{\mathrm{e}}$ classe, 70 ingénieurs de $3^{\mathrm{e}}$ classe.

Règlement concernant les činy du Corps des ingénieurs :

Les généraux-inspecteurs ne doivent pas avoir un čin inférieur à celui de lieutenant-général; les chefs d'arrondissement ne doivent pas avoir un čin inférieur à celui de général-major; les directeurs de travaux - colonels; les directeurs-conducteurs de travaux - lieutenantscolonels; les ingénieurs de $1^{\text {re }}$ classe - majors; les ingénieurs de $2^{\mathrm{e}}$ classe - capitaines; les ingénieurs de $3^{\mathrm{e}}$ classe - lieutenants ». (Cité d'après E. Sokolovskij, Pjatidesjatiletie Instituta i Korpusa Inženerov Putej Soob̌̌čenija. Istoričeskij očerk, Saint-Pétersbourg, 1859, pp. VII-VIII; voir aussi A. N. Bogoljubov, Avgustin Avgustinovič Betankur..., op. cit. (supra note 76), pp. 16-20; Kratkij istoričeskij očerk razvitija i dejatel'nosti Vedomstva Putej soobščenija..., op. cit. (supra note 76), p. 31. Sur l'Administration des ponts et chaussées française qui a servi d'exemple pour la grille de grades civils du CIVC voir « Očerk razvitija Instituta Inženerov Putej Soobščenija... », art. cit. (supra note 76), p. 27.

Notons que ce système répondait aux besoins d'un corps d'ingénieurs civils d'État (et telle était effectivement la destination du CIVC) mais que les officiers de ce corps bénéficiaient de grades civils qui les rapprochaient socialement de la garde. 
Le prince d'Oldenbourg, quant à lui, se chargea de rédiger la partie du Règlement général relative aux fonctionnaires d'État ${ }^{93}$.

L'Expédition des communications par eau «nouvelle formule » fut confirmée par l'empereur le 16 juillet 1809. Six semaines plus tard, le 30 août, elle se vit adjoindre l'Expédition pour l'aménagement des routes dans l'État ${ }^{94}$.

La résidence du directeur général fut transférée à Tver'où le prince s'installa avec sa cour. Le 12 septembre 1809, la nouvelle administration entama ses activités ${ }^{95}$. Le prince profita du déplacement vers sa nouvelle résidence pour entreprendre une tournée d'inspection et visiter, avec Dewollant et Bétancourt, les systèmes hydrauliques de la région. Les chefs des gouvernements furent priés de lui soumettre à cette occasion des rapports complémentaires concernant l'état des voies de communication sur les territoires de leur ressort.

Réunis à Tver', tous les participants de la tournée d'inspection reconnurent à l'unanimité que le document élaboré à Pavlovsk répondait, dans son ensemble, aux besoins réels du domaine des transports. En octobre, après quelques retouches, le projet repartit vers Saint-Pétersbourg, emporté par l'aide-de-camp du prince, le colonel Sabir ${ }^{96}$. Cependant, pour accélérer sa progression dans les tréfonds de la machine bureaucratique qui l'avait englouti, Dewollant dut se déplacer en personne car l'affaire commençait à traîner. Son effort fut récompensé : le 20 novembre 1809 deux documents fondateurs - le Manifeste et le Règlement concernant l'administration des voies de communication - furent confirmés par l'empereur dans leur version définitive ${ }^{97}$. C'est alors que naît, statué par ledit Règlement, le Corps des ingénieurs des voies de communication organisé « sur le mode militaire ».

Notons, pour trancher la question, qu'une autre date citée dans certaines sources pour la fondation du nouveau corps - le 13 mars 1810 - ne contredit en rien la

93. Cette question a suscité de nombreux différends au sein de la Commission. Bétancourt et Dewollant insistaient sur l'allègement nécessaire de l'appareil bureaucratique. Réduire les effectifs des fonctionnaires de bureau, en ne gardant que trois bureaux sur six, leur paraissait une bonne mesure pour assurer une transmission efficace du pouvoir au sein de l'administration jusqu'aux ingénieurs, responsables réels des travaux. Les fonctionnaires, de leur côté, opposèrent une résistance farouche à ceux qui voulaient porter atteinte à leur statut et Oldenbourg, prudent, préféra les ménager pour éviter les tensions au départ. La suggestion des deux contestataires ne fut donc pas prise en compte et, le 16 juillet 1809, le prince fit confirmer par l'empereur son projet d'organisation de l'Expédition des communications par eau qui maintenait l'appareil bureaucratique dans son intégrité. PSZ, XLI, 1 (Ukazatel' hronologičeskij), Saint-Pétersbourg, 1830, p. 723. Cependant ce n'était, en fait, qu'un détour tactique visant à calmer les passions et à gagner du temps car, au fond, l'emprise des fonctionnaires gênait le prince tout autant que ses généraux et l'imminence des changements s'imposait à tous, et en premier lieu à l'empereur. Le projet adopté fut donc considéré comme provisoire jusqu'à la confirmation du Règlement définitif du nouveau corps.

94. PSZ, Ibid., p. 726.

95. L'ancien Département des communications par eau fut liquidé et sommé de faire le bilan de ses activités pour le 1 er janvier 1810 .

96. En récompense de leur travail, Oldenbourg et Bétancourt avancèrent en grade : le prince devint général-en-chef et l'Espagnol - lieutenant-général. Dewollant fut d'abord oublié mais deux mois plus tard on se ravisa et il reçut satisfaction : l'ordre d'Alexandre Nevsky et des terres en Lituanie avec un bail de douze ans.

97. PSZ, XXX, n² 23996 du 20.11.1809, pp. 1305-1339. 
première $^{98}$. Les historiens qui la donnent tiennent tout simplement compte d'un autre document fondateur signé et confirmé quatre mois après le Règlement - la liste des effectifs du corps qui marque le début de la carrière professionnelle dans son sein de nombre d'officiers des voies de communication ${ }^{99}$.

Le 11 août 1810, la nouvelle organisation reçut officiellement le nom sous lequel elle est connue dans l'histoire - «Corps des ingénieurs des voies de communication ${ }^{100}$. Le problème des effectifs fut un de ceux qui donnèrent le plus de soucis aux fondateurs. Comme l'écrit Dewollant, il n'y avait au début que 92 candidats pour environ 200 postes d'officier vacants ${ }^{101}$. Les ingénieurs militaires étaient évidemment bienvenus mais ils furent peu nombreux à se présenter. On se vit donc obligé de procéder au recrutement d'un contingent disparate : étrangers plus ou moins compétents, officiers d'artillerie, fonctionnaires des mines, arpenteurs ou même ex-fonctionnaires du DVC dissout. Le problème fut réglé grâce à l'ukase impérial du 22 mars 1810 autorisant le recrutement dans le corps de fonctionnaires civils ayant des connaissances en ingénierie. C'est ainsi que furent incorporés, avec le grade de général-major, le chambellan Leont'jev et le gentilhomme de la chambre Sablukov; d'autres, tel le conseiller d'État Waxel, furent admis avec le grade de colonel, etc. ${ }^{102}$.

Cette période de démarrage favorisait l'avancement rapide car le recrutement initial offrait la possibilité de brûler quelques grades et d'accéder ainsi à des postes supérieurs que normalement il n'aurait pas été possible d'espérer (ainsi Sénovert, capitaine démissionnaire, fut admis dans le nouveau corps avec le grade de généralmajor, etc.). Cependant, on se ravisa bientôt et l'ukase du 18 octobre 1810 rétablit l'équilibre : les étrangers qui entraient au service russe ne purent dorénavant y être admis qu'avec les grades équivalents à ceux de leur service d'origine ${ }^{103}$. Un autre ukase suivit, en mars 1811, précisant que « personne ne pourra plus être recruté dans le Corps [...] que sur ordre Suprême spécial ou sur épreuve subie à l'Institut des ingénieurs des voies de communications ». Le 30 juillet, ces règles furent étendues aux étrangers « jusqu'à ce que le Corps fût au complet et jusqu'à ce que l'Institut dudit Corps [ICIVC] fût en état de lui fournir des officiers en nombre suffisant ${ }^{104}$.

98. L. F. Nikolai, Kratkie istoričeskie dannye o razvitii mostovogo dela..., op. cit. (supra note 82), p. 37.

99. RGIA, f. 159, op. 1, d. 520, ff. 1-2; d. 528, 26 f.; f. 207, op. 10, d. 813, 6 f.; op. 15, d. 23, ff. 188-189; op. 16, d. 71, ff. 290-297.

100. Prikazy, otdannye po Korpusu Inženerov putej soob̌̌čenija v 1810, 1811, [...] 1823 godah, Saint-Pétersbourg, 1825, p. 16; E. Sokolovskij, Pjatidesjatiletie Instituta i Korpusa Inženerov Putej Soobščenija..., op. cit. (supra note 92), p. 87.

101. F. De Wollant, Précis de mes services en Russie..., op. cit. (supra note 83), f. 83v.

102. Kratkij istoričeskij očerk razvitija i dejatel'nosti Vedomstva Putej soobščenija..., op. cit. (supra note 76), pp. 33-34.

103. Sobranie Postanovlenij do Voennogo Upravlenija Putej Soobščenija otnosjaščihsja, 1: S 1809 po 1817 g., Saint-Pétersbourg, 1834,p. 52.

104. Ibid., pp. 91-92; Prikazy, otdannye po Korpusu Inženerov putej soobščenija v 1810, ..., op. cit. (supra note 100), p. 28. 
L'Institut, quant à lui, se mit à l'œuvre dès le $1^{\text {er }}$ novembre $1810^{105}$. La tournure que prirent les événements politiques rendit sa tâche encore plus difficile. Malgré tout, les trois directeurs généraux qui se succédèrent à la tête des voies de communication durant la première décennie de son existence - Oldenbourg (18.04.180915.12.1812), Dewollant (15.12.1812-30.11.1818) et Bétancourt (1.04.18192.08.1822) - ne ménagèrent pas leurs efforts pour alimenter le corps en spécialistes hautement qualifiés : jeunes ingénieurs sortant de l'ICIVC, polytechniciens français ou anciens élèves de l'Escuela de caminos y canales de Madrid. Le but final de cette politique fut atteint par Bétancourt qui, par un coup de force opéré dès le lendemain de sa nomination, évacua du corps les techniciens praticiens en les faisant muter au Détachement de construction des voies de communication, organisme nouvellement créé à son instigation par l'ukase impérial du 17 avril 1819106. Réforme parfaitement réussie mais qui, en retour (et comme cela arrive souvent), finit par écraser son initiateur en causant d'abord sa chute, puis sa mort ${ }^{107}$.

Paradoxalement, Bétancourt, l'un des créateurs du corps militarisé comme forme spécifique de l'organisation des ingénieurs et de l'institut militarisé destiné à former ses effectifs, n'a pas survécu à leur militarisation effective opérée au lende-

105. L'histoire de cette institution a fait objet de nombreuses études. Elle a eu pour prototypes trois établissements étrangers : l'École polytechnique et l'École des ponts et chaussées françaises et l'Escuela de caminos y canales de Madrid. Bétancourt qui, à lui seul, fait le lien entre ces quatre institutions a tenté en Espagne et en Russie deux expériences différentes. Cf. notre article « L'Institut du Corps des ingénieurs des voies de communication... », art. cit. (supra note 16), qui comporte une analyse comparative des programmes de ces écoles. Voir également D. Ju. Guzevič, Razvitie mostostroenija v Rossii v XVIII- pervoj polovine XIX veka..., op. cit. (supra note 16)

106. Le Détachement militaire de construction des voies de communication (Stroitel'nyj otrjad voenno-rabočej brigady putej soobščenija) était un corps technique (mais pas d'ingénieurs !) qui, selon l'idée de Bétancourt, devait regrouper les officiers du CIVC dépourvus de formation spéciale. Cf. A. N. Bogoljubov, Avgustin Avgustinovič Betankur... op. cit. (supra note 76), pp. 60-61, 82-83; Kratkij istoričeskij očerk razvitija i dejatel'nosti Vedomstva Putej soobščenija..., op. cit. (supra note 76), pp. 49-50; E. Sokolovskij, Pjatidesjatiletie Instituta $i$ Korpusa Inženerov Putej Soobščenija...., op. cit. (supra note 92), pp. 103-105; S. M. Žitkov, Institut Inženerov putej soobščenija Imperatora Aleksandra I. Istoričeskij očerk, Saint-Pétersbourg, 1899, p. 36; PSZ, XXXVI, n 27759 du 17.04.1819 (Ob učreždenii Stroitel'nogo otrjada Voenno-rabočej Brigady Putej Soobščenija), pp. 135-136. Cette nouvelle situation désavantageait beaucoup les personnes mutées : censées garder leurs anciens grades et appointements, elles voyaient leur situation sociale considérablement abaissée; les ingénieurs qui bénéficiaient d'un statut privilégié, égal à celui de la garde, passaient au rang de techniciens avec un statut égal à celui des officiers de l'armée. C'est le mécontentement et les intrigues des anciens fonctionnaires, les premiers à être concernés par la réforme de Bétancourt, qui ont finalement causé la chute de ce dernier. Cf. D. Gouzévitch, I. Gouzévitch, « Note de l'ingénieur-colonel Raucourt de Charleville concernant des voies de communication en Russie », Cahiers du Monde russe, 37, 4, 1996, pp. 479-504; D. Gouzévitch, I. Gouzévitch, H. Vérin, J. Guillerme, " "Gospodin Rokur, kotorogo ja ljublu..." (Antuan Rokur de Sharlevil'. K 200-letiju so dnja roždenija) », Voprosy istorii estestvoznanija i tehniki, 3, 1989, pp. 76-88; D. Ju. Guzevič, I. D. Guzevič, Bazen Petr Petrovič (Bazain Pierre Dominique) 1786-1838, ..., op. cit. (supra note 16).

107. Pour l'histoire du Corps des ingénieurs des voies de communication, outre les sources citées dans la note qui précède, voir «Očerk razvitija Instituta Inženerov Putej Soobščenija... », art. cit. (supra note 76). Notons que toutes les dates concernant les événements qui ont eu lieu en Russie sont citées d'après le calendrier julien qui, au XIX siècle, avait douze jours de retard par rapport au calendrier grégorien. 
main de sa propre démission. La militarisation que visait l'Espagnol avait un sens avant tout statutaire n'affectant en rien les fondements-mêmes du métier. Son successeur, le duc de Wurtemberg, se montra beaucoup plus radical : la militarisation qu'il tenta en 1823 imposa une discipline très rigide sur l'ensemble des activités des membres du CIVC. Les historiens s'accordent à penser que cette réforme, jugée désastreuse par Bétancourt, contribua à accélérer sa finn ${ }^{108}$.

\section{Réaction en chaîne}

La nouvelle organisation professionnelle mise en place par Bétancourt et par ses collègues eut des effets spectaculaires. Le fait même de son existence déclencha, dès le milieu des années 1820 , une vraie réaction en chaîne dans la création ou la réorganisations des corps d'ingénieurs sur le mode militaire ou militarisé qui ne s'acheva que vers la fin du règne de Nicolas Ier (en 1855) ${ }^{109}$.

Parmi les anciens corps réorganisés sur ces bases nouvelles, il faut citer avant tout le Corps du génie militaire placé sous le patronage du grand-duc Nicolas Pavlovitch, futur Nicolas I ${ }^{\mathrm{er}}$. Sa réforme, lancée le 1er janvier 1819, avait beaucoup de points communs avec celle de Bétancourt opérée trois mois plus tard. Elle visait essentiellement à créer sa propre élite. Pour ce faire, les effectifs du corps furent repartis en deux groupes : les ingénieurs de campagne (l'élite) et les ingénieurs de garnison chacun constituant, en fait, un corps à part ${ }^{110}$.

108. «En 1823 l'idée du Général Bétancourt concernant le renforcement de la formation militaire des élèves de l'Institut [...] fut mise en application, peut-être beaucoup plus que l'ancien inspecteur de l'Institut [Bétancourt - I.D.G.] ne le souhaitait ». S. M. Žitkov, Institut Inženerov putej soobščenija Imperatora Aleksandra I..., op. cit. (supra note 106), p. 43. Voir aussi A. N. Bogoljubov, Avgustin Avgustinovič Betankur ..., op. cit. (supra note 76), pp. 112-113.

109. Une étude érudite de Guislaine Alleaume nous a révélé tout récemment l'histoire de la création d'un corps technique militarisé organisé selon des principes très semblables dans un autre État oriental, en Afrique. Il s'agit du Corps des irrigations en Égypte fondé en 1834 avec pour prototype le Corps des ponts et chaussées français. Cependant, à la différence de ce dernier, le corps égyptien avait une double grille de grades - civile et militaire. G. Alleaume, « La mise en place du Corps des irrigations en Égypte (1821-1835) : entre tradition nationale et imitation de l'Europe », in I. Gouzévitch, P. Bret, eds, Naissance d'une communauté internationale d'ingénieurs (première moitié du XIXe siècle). Actes de la journée d'étude (15-16 décembre 1994, CRHST, Cité des Sciences et de l'Industrie, Paris), Paris, 1997.

110. Cf. I. Fabricius, Voenno-inženernoe vedomstvo..., op. cit. (supra note 24); A. Savel'ev, Istoričeskij očerk inženernogo upravlenija $v$ Rossii, op. cit. (supra note 35); L. E. Šepelev, Tituly, mundiry, ordena v Rossijskoj imperii, op. cit. (supra note 55) ; Z. K. Novokšanova, Fedor Fedorovič Šubert, voennyj geodezist, op. cit. (supra note 61) ; A. L. Apuhtin, Očerk istorii Konstantinovskogo Meževogo instituta s 1779 po 1879 god, Saint-Pétersbourg, 1879, 350 p.; Bjalokoz, « Glavnoe gidrografičeskoe upravlenie », Sbornik kratkih svedenij po Morskomu vedomstvu, Saint-Pétersbourg, 16, 1908, 9 p.; I. A. Byhovskij, Rasskazy o russkih korablestroiteljah, Leningrad, Sudostroenie, 1966, pp. 27, 154-176, 279; «Gornyj korpus », in S. N. Južakov, ed., Bol'šaja enciklopedija, Saint-Pétersbourg, [s.d.], 7, p. 291; K.-K., «Korpusa morskogo vedomstva », in Enciklopedičeskij slovar', Saint-Pétersbourg, F.A. Brokgauz, I.A. Efron, 1895, 16 (d/t 31), p. 332; V. Sobičevskij, « Korpus lesničih », in Ibid., p. 335; Ministerstvo vnutrennih del, 1802-1902. Istoričeskij očerk, Priloženie 2 : Počta i telegraf v XIX stoletii, Saint-Pétersbourg, 1902, pp. 160-162; PSZ, 2e ed., XXIV, 1, nº 23227 du 6.05.1849, 
Parmi les organismes institués durant cette période ou un peu plus tard on peut citer : le Corps des ingénieurs de la garde (1820) ; le Corps des cartographes militaires (1822); le Corps des ingénieurs navals (1826); le Corps des pilotes de la flotte (1827) ; le Corps du génie maritime (1827/1828); le Corps des ingénieurs des mines (réorganisé, de fait, sur le mode militaire en 1834); le Corps des ingénieurs des forêt (1839) ; le Corps des ingénieurs des colonies militaires (1843) ; le Corps des ingénieurs-arpenteurs (1849) ; le Corps des ingénieurs-mécaniciens de la flotte (1854) ; le Corps de la télégraphie; le Corps des hydrographes (1912), etc. Sans oublier le Corps du génie des ponts et chaussées en Pologne et quelques corps dans le grand-duché de Finlande.

Du point de vue de la formation des cadres tous ces corps peuvent être repartis en deux groupes principaux : ceux qui avaient leur propres écoles et ceux qui n'en avaient pas.

Outre le CIVC avec son fameux Institut, certains autres corps recrutaient leurs effectifs dans des écoles techniques spécialisées, tels les Corps des ingénieurs de campagne et de garnison (École générale du génie, 1819) ${ }^{111}$, le Corps d'artillerie (École d'artillerie, 1820) ${ }^{112}$, le Corps des ingénieurs des mines (Institut du Corps des ingénieurs des mines, né de la réorganisation, en 1834/1835, de l'ancien Corps des cadets des mines), le Corps des topographes militaires (École de topographie militaire, 1822), le Corps des ingénieurs des forêts (Institut des forêts et de l'arpentage géométrique, né en 1837 de la réorganisation de l'Institut pratique des forêts) $)^{113}$.

Les Corps des ingénieurs des colonies militaires, du génie maritime et d'autres, dépourvus d'établissements scolaires propres, vivaient aux dépens des leurs voisins, en recrutant leur personnel parmi les élèves de l'ICIVC ou de l'École générale du génie. Le potentiel universel de ces deux écoles était tel que nous trouvons leurs anciens élèves dans la plupart des corps techniques de l'époque.

p. 256 ; A. A. Razdolgin, Ju. A. Skorikov, Kronštadtskaja krepost', Leningrad, Strojizdat, 1988, 420 p.; RGIA, f. 405, op. 2, 1831-1832, d. 3020, 29 f.; Z. K. Novokšanova-Sokolovskaja, Kartografičeskie i geodezičeskie raboty v Rossii v XIX - načale XX v., Moscou, Nauka, 1967, pp. 12, 122; RGIA, f. 210, op. 1, d. 4,f. 47.

111. En 1855, les classes d'officiers de cette école ont été réorganisées en Académie du génie Nikolaevskaja.

112. Les classes d'officiers de l'École d'artillerie subissent en 1855 une réorganisation du même type que celle de l'École du génie en donnant naissance à l'Académie d'artillerie Mihailovskaja.

113. Cf. Z. K. Novokšanova, Fedor Fedorovič Šubert, voennyj geodezist, op. cit. (supra note 61) ; Z. K. Novokšanova-Sokolovskaja, Kartografičeskie i geodezičeskie raboty... op. cit. (supra note 110) ; Grodskij, Mihajlovskoe artillerijskoe učilišče, 1, Saint-Pétersbourg, 1905; I. Maksimovskij, Istoričeskij očerk razvitija Glavnogo Inženernogo učilišča 1819-1859, SaintPétersbourg, 1869, 208-184 p.; «Mihajlovskoe artillerijskoe učilišče », in Sankt-Peterburg, Petrograd, Leningrad. Enciklopedičeskij spravočnik, Moscou, BRE, 1992, p. 379; [D. Guzevič], «Voenno-inženernaja akademija », Ibid., p. 119; «Voenno-topografičeskoe učilišče », Ibid., p. 122; A. Solodov, V. Kurov, « Starejšaja akademija Rossii », Nauka i žizn', 12, 1980, pp. 86-94; Voenno-inženernaja akademija imeni V. V. Kujbyševa : 150 let, Moscou, Izd-e VIA, 1969, 544 p. Voir aussi les documents cités supra dans la note 68. 


\section{Les corps, l'Académie des sciences et la spécificité de l'école du génie russe}

Que peut nous apprendre l'histoire du développement des corps techniques russes que nous venons de tracer dans ses grandes lignes? Quelle est la spécificité de ce type d'organisation par rapport aux autres organisations professionnelles connues à l'époque (comités scientifiques, académies, associations et sociétés savantes, techniques et d'ingénieurs, clubs professionnels, collèges invisibles, réseaux de sociabilité, congrès, expositions, etc.) ?

Le rapprochement n'est pas fortuit. Rappelons que les académies et certaines sociétés savantes possèdent leur propre hiérarchie de grades assez bien structurés (par exemple les membres actuels et honoraires, membres-correspondants et étrangers, etc.). Aussi similaires qu'elles puissent paraître, ces structures se distinguent par plusieurs points de celles des corps.

Ainsi les grades académiques personnels, même s'ils reflètent la qualification et les mérites de leurs porteurs, sont avant tout appelés à associer à l'activité de telle ou telle compagnie savante des individus qui ne font pas partie de ses effectifs, y compris ceux qui résident à l'étranger. D'autre part le grade de «membre honoraire » a pour fonction de rendre hommage aux personnalités placées aux plus hauts échelons de la pyramide sociale, comme les membres des familles impériales, royales et princières, les ministres, les favoris, etc. ${ }^{114}$ En règle générale, faire partie d'une compagnie savante ou exercer en son sein, même en qualité de membre actuel, n'est pas une profession et encore moins une source principale de revenus. Par contre, la plupart des associations de ce type exigent de leurs membres des cautions plus ou moins régulières. De plus, bon nombre de ces organismes - et ceci les distingue nettement des corps - ont un statut autonome et ne relèvent pas de l'État, même s'ils sont patronnés ou protégés par celui-ci.

Une question se pose : peut-on créer une compagnie savante qui répondrait à toutes les exigences d'un corps? Autrement dit, peut-on créer une association professionnelle de savants relevant de l'État et munie d'une grille de grades structurée reflétant principalement la qualification et les mérites de ses membres qui jouiraient alors du statut de fonctionnaires salariés? Il existe un antécédent fourni, encore une fois, par l'histoire russe : la fameuse Académie des sciences de SaintPétersbourg, créée sur l'initiative de Pierre Ire en 1725. La conclusion qu'on peut en tirer sera paradoxale mais non controversée : les effectifs de cette respectable compagnie savante formaient de facto un corps savant élitaire. C'est ce qui la distingue principalement de ses homologues occidentales que ce soit la Royal Society of London, l'Académie des sciences de Paris ou l'Akademie der Wissenschaften zu Berlin. En même temps cet exemple révèle, peut-être plus que tout autre, l'adéquation parfaite de cette forme d'organisation professionnelle aux conditions de la Russie.

114. Nous ne parlons pas ici des grades scientifiques qui reflètent le niveau de qualification personnelle d'un chercheur. 
Les racines de cette adéquation sont à rechercher, nous semble-t-il, dans le rôle que l'État russe jouait dans le vie du pays ou, plus profondément encore, dans l'essence même de cet État. Un système de corps professionnels d'ingénieurs ne peut, en effet, subsister que dans un État au pouvoir centralisé fort qui le structure et le maintient. Pourtant, cette dépendance est ambivalente car la puissance de l'État, son potentiel régulateur, sa capacité d'assurer le contrôle efficace de la société qu'il gouverne sont, à leur tour, fonctions de la puissance et de la ramification des structures corporatistes professionnelles qu'il engendre. Tous ces traits ont d'autant plus de chances de se développer que le nombre de corps techniques civils est grand. Nous avons bien dit « les corps civils », puisque c'est eux et non pas les corps techniques militaires (qui de toute façon émergent partout où existent les armes techniques) qui sont les meilleurs indicateurs du degré de l'emprise de l'État sur la vie de la société. La prolifération des corps civils militarisés dans l'Empire russe au XIX ${ }^{\mathrm{e}}$ siècle n'est, dans ce contexte, que la sécrétion normale d'un organisme absolutiste à fortes tendances totalitaires, la démonstration ostensible de sa volonté de pénétrer toute la vie sociale, professionnelle et intellectuelle du pays.

Enfin, une dernière question : quel fut l'impact de ce système d'organisations professionnelles corporatives sur le développement de l'art et des sciences de l'ingénieur dans le pays? Cette question se scinde tout naturellement en deux autres : quel fut le potentiel d'un tel système et comment fut-il réalisé?

Pour aller directement au coeur du sujet dégageons d'emblée un trait qui nous semble fondamental dans ce contexte : le statut des membres du corps qui est celui des ingénieurs d'État. Fonctionnaires de l'État aux revenus stables garantis par leur service, ces ingénieurs sont libres de toute contrainte financière et de toute quête de bénéfices rapides contrairement aux entrepreneurs installés à leur propre compte. Leur tâche principale et bien définie par les instructions de service, qui sont strictes sur ce point, consiste donc à veiller aux intérêts économiques de l'État en cherchant à rentabiliser au maximum les travaux qu'ils mènent à ses frais. Réduire le coût des ouvrages d'art par l'application de méthodes économiques fondées sur les dernières réalisations des sciences de l'ingénieur, mobiliser leurs compétences et leur potentiel intellectuel afin de donner aux solutions techniques les formes les plus performantes, tels sont leurs mobiles principaux et les perspectives de leur activité à long terme ${ }^{115}$. Autrement dit, l'organisation des ingénieurs en corps a ceci de particulier qu'elle offre à leurs officiers à la fois un encadrement institutionnel solide, une existence assurée et une marge de liberté intellectuelle suffisante pour qu'ils puissent agir sans se soucier du rendement immédiat de leur travail. Cette absence de contraintes temporelles et pécuniaires stimule aussi bien les recherches théoriques de longue haleine que les innovations susceptibles d'être diffusées sans encombre à l'échelle du pays.

115. Cette préoccupation est également commune aux ingénieurs exerçant au sein des manufactures d'État : usines métallurgiques et de fabrication mécanique, salines, verreries, poudreries, etc. 
Une telle approche aurait été difficilement imaginable dans un État qui, comme la Grande-Bretagne, privilégiait la libre entreprise et où les ingénieurs se concentraient essentiellement dans l'industrie privée ou bien étaient eux-mêmes entrepreneurs.

\section{Les sciences de l'ingénieur et le projet académique : pragmatisme contre idéalisme}

Le modèle de l'activité professionnelle réalisé dans l'Empire russe fut, en fait, un hybride, né au cours du XVIII siècle, composé d'une synthèse complexe des ambitions impériales et des expériences occidentales savamment sélectionnées. Le type d'ingénieur-chercheur, si caractéristique pour l'école russe du génie fut, lui aussi, le fruit de cette conjoncture qui débuta à l'époque de Pierre Ier.

Les ambitions du tsar-réformateur allaient effectivement bien au-delà de l'état réel des sciences et des techniques dont il pouvait alors disposer. Deux tendances opposées ont convergé dans sa politique, faisant preuve à la fois de son esprit pragmatique et de sa perspicacité. Si, au début de ses réformes (1701-1719), il crée une poignée d'écoles d'ingénieur pratiques qui dispensent les «sciences pour le développement » (c'est-à-dire les savoirs utiles d'application immédiate), il lance juste avant sa mort une autre opération qui semble beaucoup moins évidente du point de vue pratique. Fonder en 1725 une Académie des sciences peut effectivement paraître un acte purement volontariste et dépourvu de logique dans un pays où les hommes instruits sont rares et les savants quasi inexistants. L'institution créée comme « un exemple idéal à imiter » et destinée à développer «les sciences pour les sciences » a pourtant offert assez de preuves de sa vitalité; avec l'université et le gymnasium académiques elle est arrivée à combler progressivement le vide intellectuel dans le domaine de la recherche. Elle a également contribué à élever la recherche au rang d'activité respectable sinon privilégiée et à affirmer aux yeux de l'opinion publique la primauté de la théorie sur l'empirisme (et ceci dans un pays où un enseignement secondaire quelque peu développé faisait défaut !).

La convergence de ces deux types d'activité na pas été immédiate. Il a fallu un siècle avant que le gouffre qui séparait les occupations des académiciens de celles des ingénieurs-praticiens ne se resserre. Un siècle marqué, entre autres, par la coexistence et l'influence réciproque de deux systèmes d'enseignement parallèles - fondamental et pratique. Cette symbiose sacrée par la tradition a prédéterminé le choix, au début du siècle suivant, du modèle français d'enseignement technique supérieur qui, en retour, a donné un souffle nouveau à la formation des ingénieurs russes ${ }^{116}$.

116. La prise en compte des prototypes français (l'École polytechnique et les écoles d'application) a accéléré et révolutionné le processus en cours au sein du pays. Depuis la deuxième moitié du XVIII ${ }^{e}$ siècle, les écoles techniques nationales de niveau secondaire, déjà solidement établies, entament une lente progression vers l'enseignement supérieur. Cette volonté se manifeste par la part toujours croissante de la théorie dans les cursus scolaires, par un effort continu d'élever le statut social des promotions sortantes. Une poignée d'ingénieurs-savants russes font leur 


\section{La recherche dans les corps et sa valorisation}

\section{L'activité scientifique dans les corps était considérée comme la manifestation d'un} « zèle de service », elle était donc encouragée et généreusement récompensée. Un ouvrage réussi pouvait apporter à son auteur un cadeau important, une prime d'argent considérable ou même un avancement anticipé. Les titres académiques étaient autant de récompenses prestigieuses. Devenir membre honoraire de l'Académie des sciences, et donc s'élever au rang de l'élite intellectuelle du pays, apparaissait comme un honneur auquel les princes de sang se montraient tout aussi sensibles que les officiers des corps qu'ils dirigeaient ${ }^{117}$.

apparition sur la scène nationale. Outre le célèbre Mihail Lomonosov, ingénieur des mines de par sa seconde formation, on peut citer dans cette lignée S. Gur'ev, V. Viskovatov, P. Gamaleja - tous mathématiciens et mécaniciens remarquables, protagonistes et promoteurs de l'enseignement théorique. Cf. A. P. Juškevič, « Akademik S. E. Gur'ev i ego rol' v razvitii russkoj nauki », Trudy Instituta istorii estestvoznanija, Moscou, 1, 1947, pp. 219-268; V. E. Prudnikov, « K biografii akademika S. E. Gur'eva », Ibid., 10, 1956, pp. 384-392.

Avec la mise en place, dans les années 1810-1830, d'un système de grandes écoles, la formation théorique se voit légitimée à l'échelle du pays : elle devient non seulement accessible mais obligatoire pour tout ingénieur qui se prépare à rentrer dans un corps technique. La recherche devient un champ d'activité professionnelle autonome qui dispose de son contingent propre recruté parmi les meilleurs esprits techniques de l'époque. Leur activité embrasse des domaines très variés des sciences fondamentales et appliquées, telles la géométrie descriptive (promoteur russe V. Sevast'janov), la mécanique rationnelle (K. Janiš qui était aussi créateur de la théorie des échecs), la mécanique appliquée (N. Jastržembskij), la cristallographie et la géologie (E. Fedorov), la physique expérimentale (P. Lebedev). Les ingénieurs-praticiens étaient, eux aussi, susceptibles de mener, à l'occasion, des recherches scientifiques et expérimentales de très haut niveau, compétitives à l'échelle internationale. Citons, à titre d'exemple, les travaux de D. Žuravskij qui, en étudiant les fermes Haw, a découvert les contraintes tangentielles et a créé la méthode du calcul des systèmes de barres. Cf. S. Ja. Grodzenskij, Šahmaty v žizni učenyh, Moscou, Nauka, 1983, pp. 11-15; V. A. Gusev, « Pervyj russkij professor načertatel'noj geometrii Ja. A. Sevast' janov », Trudy Instituta istorii estestvoznanija, 4, 1952, pp. 184-194; « Janiš, Karl Andreevič », in Russkij biografičeskij slovar', [25] (Jablonovkij-Fomin), pp. 133-134 (Reprint, New York, Kraus Reprint Corporation, 1962) ; E. N. Rakčeev, Dmitrij Ivanovič Žuravskij 1821-1891, Moscou, Nauka, 1984, 240 p.; B. F. Tarasov, Jakov Aleksandrovič Sevast'janov 1796-1849, Saint-Pétersbourg, Nauka, 1995, 189 p.

117. Le prince d'Oldenbourg et le duc de Wurtemberg, tous deux membres de la famille impériale et directeurs successifs du CIVC, furent élus académiciens honoraires en décembre 1810 . Le Moniteur Universel, 18, 18.01.1811, p. 67.

D'ailleurs, le fondateur de la tradition fut le premier à en donner l'exemple : en 1717, Pierre Ier accepta comme signe d'honneur son élection à l'Académie des sciences de Paris. Cf. « Addition à l'histoire de M.DCCXX », Histoire de l'Académie Royale des sciences, Année M.DCCXX, Paris, 1720, pp. 125-132; Delisle l'Aîné, « Détermination géographique de la Situation et de l'étendue des différentes parties de la Terre », Ibid., pp. 365-384; Id., « Remarques sur la Carte de la mer Caspienne », Ibid., [...] M.DCCXXI, 1723, pp. 245-254; «Éloge du Czar Pierre I », Ibid., [...] M.DCCXXV, 1725, pp. 105-128; N. A. Baklanova, «Kul'turnye svjazi Rossii s Franciej v pervoj četverti XVIII v. », in Meždunarodnye svjazi Rossii v XVII-XVIII vV. (ekonomika, politika i kul'tura). Sbornik statej, Moscou, Nauka, 1966, pp. 303-344; Duclos, Mémoires secrets sur les règnes de Louis XIV et de Louis XV, Paris, Foucault, 1829, pp. 266-281 (Collection des mémoires relatifs à l'histoire de France, 76) ; I. L. Fejnberg, Abram Petrovič Gannibal praded Puškina. Razyskanija i materialy, 2e ed., Moscou, Nauka, 1986, 129 p.; A. Galitzin, « Pierre Ier, membre de l'Académie des sciences », Bulletin du Bibliophile et du Bibliothécaire, septembre 1859, pp. 611-617; A. T. Grigor'jan, A. P. Juškevič, « Materialy po istorii otečestvennoj nauki v arhivah Pariža », Voprosy istorii estestvoznanija i tehniki, 17, 1964, pp. 118-120; Histoire et prestige de l'Académie des sciences 1666-1966, [Paris], Musée du CNAM, 1966, pp. 99-103; B. P. Ivanov, «Petr I i russkaja 


\section{Le revers de la médaille ou le destin des corps techniques, 1860-1900}

Les avantages des corps techniques avaient leurs revers et le système finit par laisser apparaître ses insuffisances. Une fois la limite de leur développement atteinte, la bureaucratisation et la militarisation risquaient de se retourner contre leurs propres acquis. Des exemples de ce genre n'étaient pas rares, surtout à partir des années 1840-1850.

kartografija », Materialy Har'kovskogo otdela Geografičeskogoobščestva Ukrainy, 5, 1968,pp. 20-24; K. E. Jam, « Proizvedenija Fontenelja v Rossii v XVII-načale XIX v. », in Francuzskij ežegodnik 1979, Moscou, Nauka, 1978, pp. 180-196; E. E. Knjažeckaja, « O pričinah izbranija Petra I členom Parižskoj Akademii nauk », Izvestija Vsesojuznogo geografičeskogo obščestva, 92, 2, 1960,pp. 154-158; Id., Sud'ba odnoj karty, Moscou, Mysl', 1964, 119 p. ; Id., « U istokov russkoj botaniki (K 300-letiju so dnja roždenija Petra I) », Botaničeskij žurnal, 57, 1, 1972, pp. 139-147; Id., «Petr I - člen Francuzskoj Akademii nauk », Voprosy istorii, 12, 1972, pp. 199-203; Id., « Načalo russko-francuzskih naučnyh svjazej », in Francuzskij ežegodnik 1972, Moscou, Nauka, 1974, pp. 260-273; Id., « Naučnye svjazi Rossii i Francii pri Petre I », Voprosy istorii, 5, 1981, pp. 91-100; Id., « K voprosu ob izbranii Petra I členom Parižskoj Akademii nauk », in Issledovanija v oblasti istorii nauki i tehniki. Sbornik tezisov k oblastnoj konferencii LO SNOIFET (okt. 1988 g., Leningrad),Leningrad, 1988,pp. 110-113;E. Kniajetskaïa, « Les origines des échanges scientifiques franco-russes », Études soviétiques, mai 1972,pp. 5657; E. A. Kniajetskaïa, V. L. Chenakal, « Pierre le Grand et les fabricants français d'instruments scientifiques », Revue d'Histoire des Sciences, 28, 3, juillet 1975, pp. 243-258; N. G. Komarova, « Kaspijskoe more v trudah naturalistov-putešestvennikov XVIII-pervoj poloviny XIX v. », Voprosy istorii estestvoznanija i tehniki, 3, 44, 1973, pp. 43-48; Ju. Kovalenko, « Pod svodami dvorca Mazarini », Izvestija, 13.12.1985, p. 5; Id., «Russkie sokrovišča francuzskoj biblioteki », Ibid., 44, 13.2.1987; J. Loiseau, « Tokarnyj stanok A. K. Nartova vo Francuzskom nacional'nom hranilišče iskusstv i remesel », Voprosy istorii estestvoznanija i tehniki, 3, 1957, pp. 212-216; P. Myursepp, « Rapports entre le célèbre savant français Réaumur et le tzar Pierre Ier », in XII C Congrès international d'histoire des sciences. Actes, XI (Sciences et sociétés), Paris, Albert Blanchard, 1971, pp. 95-101; N. Pavlenko, Petr Velikij, Moscou, Mysl', 1984, pp. 378380; M. Poludenskij, « Petr Velikij v Pariže », Russkij arhiv, 5-6, 1865, col. 676-701 (2e ed., col. 63-90) ; «Putešestvie carja Petra Alekseeviča vo Franciju i prebyvanie v Pariže Ego Carskogo Veličestva », in E. S. Samonina, ed., Reka vremen, 5 : Gosudar', Gosudarstvo, Gosudarstvennaja služba, Moscou, Ellis Lak, Reka Vremen, 1996, pp. 5-19; D. Riabouchinsky, « Les rapports scientifiques entre la France et la Russie », Revue générale scientifique, 2, 1934,pp. 4650 (communiqué par A. Grelon) ; [Saint-Simon], « O prebyvanii Petra Velikogo v Pariže, v 1717 godu : Iz zapisok gercoga de-Sen-Simona », Žurnal Ministerstva narodnogo prosveščenija, 89, 1856, otd. II, pp. 1-24; Voltaire, Histoire de l'Empire de Russie sous Pierre-le-Grand, Paris, Pierre Didot l'Aîné, Firmin Didot, 1803, 2, pp. 83-86.

Cette même époque nous offre encore un exemple d'élection académique, d'ordre plutôt anecdotique : Aleksandr Men'šikov, dignitaire fameux de Pierre Irr qui, malgré tous ses talents, était analphabète, avait devancé sur ce terrain son auguste maître en s'étant fait élire membre de la Royal Society of London en 1714. Son correspondant au nom de la vénérée compagnie londonienne fut sir Isaac Newton. N. Ejdel'man, Iz potaennoj istorii Rossii XVIII-XIX vekov, Moscou, Vysšaja škola, 1993, pp. 82-88; Ju. H. Kopelevič, E. P. Ožigova, Naučnye akademii stran Zapadnoj Evropy i Severnoj Ameriki, Leningrad, Nauka, 1989, p. 95; L. V. Milov, [Compte rendu d'ouvrage] : « Nikolaj Pavlenko. Poluderžavnyj vlastelin. Istoričeskaja hronika. M., "Sovremennik", 1988 [...] », Istorija SSSR, 1, 1990, pp. 202-204; N. Pavlenko, «Aleksandr Danilovič Men'šikov », in Id., Ptency gnezda Petrova, Moscou, Mysl', 1994, pp. 20-21 ; V. S. Sobolev, Ju. A. Vinogradov, [Compte rendu d'ouvrage] : « Ju. H. Kopelevič, E. P. Ožigova. Naučnye akademii stran Zapadnoj Evropy i Severnoj Ameriki. L., 1989. 414 s. », Voprosy istorii estestvoznanija i tehniki, 1, 1991 pp. 146-148; A. Rupert Hall, Laura Tilling, eds, The correspondence of Isaac Newton, VI : 1713-1718, Cambridge-Londres, Cambridge University press, 1976, pp. 171-172, 183-185; R. S. Westfall, Never at rest : A biography of Isaac Newton, Cambridge-Londres, Cambridge University press, 1970, pp. 682, 785. 
Engendré par un État bureaucratisé et militarisé à l'extrême, le système des corps techniques répondait parfaitement aux besoins d'une gestion centralisée et globalisée. Tant que ses fonctionnaires, ingénieurs d'État enrôlés dans les corps militarisés, étaient formés en nombre suffisant, tant qu'ils restaient les maîtres du terrain et qu'ils pouvaient mener à bien n'importe quelle tâche technique, cette forme d'organisation professionnelle favorisa le développement de l'activité de l'ingénieur dans le pays. Cependant, une fois à son apogée, le système perdit de l'élan, il se rigidifia et devint plus fragile. Lorsque les limites de ses possibilités d'évolution furent atteintes, une poussée minime suffit à déstabiliser l'ensemble.

Cette poussée, ou plutôt cette mine qui contribua à l'explosion du système fut la « libre entreprise ». Le jeune capitalisme russe, énergique, entreprenant, impatient, qui dès le milieu du XIX ${ }^{\mathrm{e}}$ siècle entra en compétition avec l'État dans le domaine du génie industriel avait besoin de beaucoup de matière grise. Or les ingénieurs d'État soumis aux impératifs de leur service et à des règlements disciplinaires sévères étaient peu disponibles. Les établissements qui formaient les ingénieurs pour l'industrie privée étaient encore rares tandis que les grandes écoles des corps d'État étaient peu enclines à inclure dans leurs programmes ce type de formation : leur caractère corporatiste, spécialisé et fermé s'y opposait. «Débloquer» les corps militarisés en leur offrant une forme civile plus souple qui faciliterait la libre circulation des ingénieurs, tel fut le défi auquel l'État dut faire face dans l'intérêt de son industrialisation rapide.

Les réformes libérales d'Alexandre II destinées à adapter l'appareil administratif de l'État aux conditions nouvelles ont tenu compte de cette perspective. Hormis les corps techniques proprement militaires, tous les autres ont été réorganisés en deux ans (1866-1867) sur le mode civil. Parmi les corps concernés, citons ceux des voies de communication, des mines, de l'arpentage, des forêts, de la télégraphie, donc les organismes essentiels pour l'ensemble des travaux publics ${ }^{118}$.

Les corps «nouvelle formule » furent réorganisés selon le modèle éprouvé que nous avons appelé « le corps de facto ». Le statut civil de l'ingénieur ainsi que les modalités de son incorporation et de sa carrière ultérieure étaient régis par trois facteurs principaux :

- le grade professionnel auquel il avait droit était conditionné par la formation reçue dans l'école technique correspondante (Institut des voies de communication, Institut des ingénieurs des mines, etc.) ;

- le grade de fonction était défini par l'état des personnels de l'administration et non pas du corps lui-même;

- le čin (où le grade personnel) était déterminé selon la Table des rangs et non pas selon la grille interne du corps comme auparavant.

118. PSZ, 2e ed., XLI, otd. 1, n 43397 du 15.06.1866, pp. 685-696; otd. 2, pp. 372-373; XLII, otd. $2, \mathrm{n}^{\circ} 44897 \mathrm{du} 2.08 .1867$, pp. 3-5, 665-667. 
L'organisation en tant que corps militaire a été maintenue pour les corps de l'administration de la marine ${ }^{119}$ et pour les corps techniques militaires proprement dits, du génie, de l'artillerie, etc.

Cet assouplissement n'a pas tardé à porter ses fruits. La libéralisation de l'activité intellectuelle a accéléré le développement économique de l'Empire russe qui, vers le début du XX⿳亠丷厂犬 siècle, s'est élevé au rang des pays industrialisés.

\section{Conclusion}

Les corps techniques comme forme d'organisation professionnelle des ingénieurs dans l'Empire russe sont nés dans le courant du XVIII' siècle du besoin ressenti par l'État de rationaliser son appareil de gestion afin de mieux l'adapter aux urgences de la modernisation. La forme militaire qu'ils ont revêtue répondait parfaitement aux exigences du pouvoir centralisé qui tenait à mettre sous son contrôle l'activité productive et intellectuelle de tout le pays. En assurant à leurs fonctionnaires un statut social élevé et la garantie d'un revenu stable, ils ont favorisé à la fois le développement des pratiques et des sciences de l'ingénieur tout en ouvrant ce domaine aux innovations européennes les plus performantes.

Cependant, comme toute structure rigide, les corps militarisés avaient leur revers. Les limites de leur capacité d'évolution et le frein qu'ils mirent au développement de la libre entreprise devinrent évidents au milieu du XIX ${ }^{\mathrm{e}}$ siècle, au moment où la Russie s'engagea sur la voie de l'industrialisation. Les besoins du capitalisme naissant et la libéralisation générale de la vie du pays furent autant de raisons qui conduisirent en 1866-1867 au rejet de la forme militarisée des organisations professionnelles des ingénieurs au profit de celle, plus souple et plus dynamique, des corps civils.

L'histoire des corps techniques et de leurs réorganisations ne s'est pas arrêtée là. Elle s'est poursuivie à l'époque soviétique. Ainsi, pendant et après la Deuxième Guerre mondiale, le gouvernement soviétique, comme son prédécesseur impérial

119. Les corps de l'artillerie maritime et des pilotes de la flotte ont été supprimés en 1885, et leurs fonctions ont été reprises par les officiers de la flotte. Selon le règlement du 15 mai 1886, le Corps des ingénieurs navals et des ingénieurs-mécaniciens avait une grille de 5 grades : inspecteur de construction navale et inspecteur de partie mécanique $\left(5^{\mathrm{e}}\right.$ classe, équivalent au rang du contre-amiral) ; constructeur de vaisseaux en chef et ingénieur-mécanicien de la marine (flagmanskij inžener-mehanik; 6e classe, capitaine de $1^{\text {er }}$ rang); constructeur de vaisseaux (mladšij sudostroitel') et ingénieur-mécanicien supérieur (staršij inžener-mehanik, 7e cl.) ; assistant principal du constructeur de vaisseaux (staršij pomoščnik sudostroitelja) et assistant de l'ingénieur-mécanicien supérieur (pomoščnik staršego inžener-mehanika, 9e cl.), second assistant du constructeur de vaisseaux (mladšij pomoščnik sudostroitelja) et second ingénieurmécanicien (mladšij inžener-mehanik, $10^{\mathrm{e}} \mathrm{cl}$, lieutenant).

Le Corps des ingénieurs et techniciens de constructions maritimes a été réorganisé en 1891. La grille des grades d'ingénieurs était la suivante : inspecteur des constructions maritimes et ingénieurs-constructeurs : principal, premier et second (glavnyj, staršij i mladšij) plus deux grades de techniciens. Les officiers de ces services devançaient d'une classe ceux de l'armée. Cf. L. E. Šepelev, Tituly, mundiry, ordena v Rossijskoj imperii, op. cit. (supra note 55), pp. 104105; K.-K., « Korpusa morskogo vedomstva », in Enciklopedičeskij slovar', Saint-Pétersbourg, F.A. Brokgauz, I.A. Efron, 1895, 16 (d/t 31), p. 332. 
un siècle auparavant, a procédé à la militarisation des corps civils ${ }^{120}$. Ce changement fut-il de nouveau tributaire des besoins d'un État totalitaire et militarisé, avide de mettre sous sous contrôle toutes les formes d'activité productive et intellectuelle du pays? Faut-il rappeler aussi que l'un des premiers réflexes du libéralisme khrouchtchévien de l'époque du Dégel aura été d'assouplir cette étreinte étouffante?

L'histoire de la « Table des rangs » version soviétique, ainsi que celle de l'organisation corporatiste de l'activité des ingénieurs ont été encore très peu abordées. Leur étude serait toutefois indispensable pour dresser un tableau complet du fonctionnement de la machine bureaucratique soviétique. Notre plus grand souhait est que le survol historique que nous avons tenté dans cet article incite les historiens de l'époque soviétique à se pencher sur ces problèmes.

\section{Irina Gouzévitch}

Centre Alexandre Koyré

Museum national d'histoire naturelle

57, rue Cuvier

75005 Paris

\section{Dmitri Gouzévitch}

Centre d'histoire des techniques

Conservatoire national des arts et métiers

5, rue du Vertbois

75003 Paris

et

Rossijskaja akademija nauk

Institut istorii estestvoznanija i tehniki

e-mail :gouzevit@mnhn.fr

gouzevit@msh-paris.fr

120. Un écho intéressant à ces changements a été publié par D. Dalin, « Bližajšaja reforma Tabel' o rangah », Socialističeskij vestnik = The Socialist Courier (New-York), 23-24, 10.12.1943,pp. 274-276. 